\title{
Proteomic and physiological approaches reveal new insights for uncover the role of rice thylakoidal APX in response to drought stress
} \author{
Setsuko Komatsu ${ }^{\text {, }}$, Joaquim A.G. Silveira ${ }^{\text {a,* }}$ \\ a Departamento de Bioquímica e Biologia Molecular, Universidade Federal do Ceará, Fortaleza CEP 60451-970, Brazil \\ b Campus do Litoral Paulista, Universidade Estadual Paulista (UNESP-CLP), São Vicente CEP 11380-972, Brazil \\ ${ }^{c}$ Departamento de Genética, Universidade Federal do Rio Grande do Sul, Porto Alegre CEP 91501-970, Brazil \\ ${ }^{\mathrm{d}}$ Faculty of Environmental and Information Sciences, Fukui University of Technology, Fukui 910-8505, Japan
}

Juliana R. Cunha ${ }^{\mathrm{a}}$, Fabrício E.L. Carvalho ${ }^{\mathrm{a}}$, Milton C. Lima-Neto ${ }^{\mathrm{b}}$, Douglas Jardim-Messeder ${ }^{\mathrm{c}}$, João Victor A. Cerqueira ${ }^{a}$, Marcio O. Martins ${ }^{a}$, Adilton V. Fontenele ${ }^{a}$, Márcia Márgis-Pinheiro ${ }^{c}$,

\section{A R T I C L E I N F O}

\section{Keywords:}

Ascorbate peroxidases

Photosynthesis

Proteome

Redox metabolism

Water deficit

Oryza sativa

\begin{abstract}
A B S T R A C T
Chloroplast APX isoforms display controversial roles as $\mathrm{H}_{2} \mathrm{O}_{2}$ scavengers and signaling players in response to abiotic stress and conclusive results are lacking. We tested the hypothesis that thylakoidal APX displays an important role for drought tolerance, especially by regulating abundance of essential protein species. For this, OsApx8 RNAi-silenced rice (apx8) and non-transformed plants (NT) were exposed to mild water deficit. The drought-sensitivity in apx8 plants was revealed by decreases in shoot growth, relative water content and photosynthesis, which was accompanied by increased membrane damage, all compared to NT plants. This higher sensitivity of apx8 plants to mild drought stress was also related to a lower accumulation of important protein species involved in several metabolic processes, especially photosynthesis, photorespiration and redox metabolism. Despite apx8 plants have displayed an effective induction of compensatory antioxidant mechanisms in well-watered conditions, it was not enough to maintain $\mathrm{H}_{2} \mathrm{O}_{2}$ homeostasis and avoid oxidative and physiological disturbances under mild drought conditions. Thus, thylakoidal APX is involved in several phenotypic modifications at proteomic profile level, possibly via a $\mathrm{H}_{2} \mathrm{O}_{2}$-induced signaling mechanism. Consequently, this APX isoform is crucial for rice plants effectively cope with a mild drought condition.

Biological significance: This work provides for the first time an integrative study involving proteomic, physiological and biochemical analyses directed to elucidation of thylakoidal APX roles for drought tolerance in rice plants. Our data reveal that this enzyme is crucial for maintaining of growth and photosynthesis under mild water deficit conditions. This essential role is related to maintaining of $\mathrm{H}_{2} \mathrm{O}_{2}$ homeostasis and accumulation of essential proteins involved in several important metabolic pathways. Remarkably, for drought resistance was essential the accumulation of proteins involved with metabolism of photosynthesis, signaling, carbohydrates, protein synthesis/degradation and stress. These results can contribute to understand the role of chloroplast ascorbate peroxidases in drought tolerance, highlighting the physiological importance of key proteins in this process.
\end{abstract}

\section{Introduction}

Ascorbate peroxidases (APXs) are important antioxidant enzymes catalyzing the reduction of $\mathrm{H}_{2} \mathrm{O}_{2}$ into water using ascorbate as an electron donor [1]. In rice, two isoforms are addressed to chloroplasts, the APX7 (stromal) and APX8 (thylakoidal) [2]. In addition, rice APX6 isoform is supposed to be addressed for both mitochondria and chloroplasts [2]. Despite its potential roles in plant defense metabolism,
chlAPX are known to be highly inhibited by $\mathrm{H}_{2} \mathrm{O}_{2}$ in absence of ascorbate, which is possibly linked to an irreversible cross-linking of the protein heme group to the distal Trp41 and radical formation in Cys31 and Cys125 [3]. These mechanisms could be related to the controversy concerning the biological importance of the chlAPX in plants, especially under stressful conditions [4].

Maintaining the electron flow through the thylakoid membranes, especially under stressful conditions, is vital for preventing oxidative

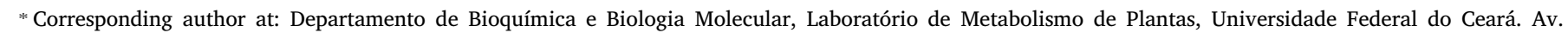
Humberto Monte 2825, Campus do Pici, Bloco 907. Fortaleza, CP 6020, CEP 60451-970, Ceará, Brazil.

E-mail address: silveira@ufc.br (J.A.G. Silveira). 
damage to chloroplasts [5]. The water-water cycle (WWC) comprehends the production and scavenging of ROS by the copper/zinc superoxide dismutases $(\mathrm{Cu} / \mathrm{Zn}-\mathrm{SOD})$ and chlAPX, besides the regeneration of non-enzymatic molecules in chloroplasts, such as DHA and MDHAR [6]. In these reactions, the membrane-attached $\mathrm{Cu} / \mathrm{Zn}-\mathrm{SOD}$ convert the $\mathrm{O}_{2}{ }^{-}$produced in PSI to $\mathrm{H}_{2} \mathrm{O}_{2}$. Subsequently, thylakoidal APX is supposed to act as the first line of ROS scavenging, reducing $\mathrm{H}_{2} \mathrm{O}_{2}$ back into water using ascorbate as an electron donor. Also, $\mathrm{H}_{2} \mathrm{O}_{2}$ could be removed by stromal APX (sAPX) as a second defense layer in stroma, avoiding $\mathrm{H}_{2} \mathrm{O}_{2}$ accumulation [7]. Thus, chlAPXs, especially thylakoidal APX, have been considered to be a bottleneck in the water-water cycle, at least in higher plants, because of their high susceptibility to $\mathrm{H}_{2} \mathrm{O}_{2}$ [2]. This characteristic may affect the capacity of plants to tolerate stress, which should make this a good gene-target for improving plant stress tolerance [3].

Several studies have failed to find a "stress-sensitive phenotype" among chlAPX loss-of-function mutants [8-11]. Works involving Arabidopsis thaliana transformed plants deficient in sAPX and/or tAPX isoforms have suggested for a minor importance of these enzymes in the plant growth and development [8-10]. Indeed, these plants do not display any visible phenotypic alterations under non-stressful growth conditions. In opposition, under photooxidative stress, tAPX knocked out mutants exhibited increased accumulation of $\mathrm{H}_{2} \mathrm{O}_{2}$ and oxidized proteins, rather than SAPX knocked out plants [10]. In rice, similar results have been reported for plants silenced by RNAi for cytosolic, peroxisomal and chloroplastic APX isoforms [11-13]. These plants exhibited normal growth as compared to non-transformed (NT) plants and a great tolerance to several abiotic stress conditions [13,14]. Remarkably, double chlAPX knockdown rice plants exhibited no differences in terms of photosynthetic performance under severe high light stress [11].

Recently, much have been discussed about a more complex function of these enzymes, acting not only as classic peroxidase proteins, but also as regulators of retrograde $\mathrm{H}_{2} \mathrm{O}_{2}$ signaling in order to fine-tuning abiotic and biotic stress responses [15]. Therefore, two important questions are still open: 1) Which is the real physiological importance of chloroplastic APX isoforms under abiotic stress conditions? 2) Which are the protein species/pathways regulated by thylakoidal APX activity or downstream $\mathrm{H}_{2} \mathrm{O}_{2}$ levels involved in tolerance/sensitivity against abiotic stress conditions? Particularly, in response to water deficit stress, the studies involving the role of chloroplast APX are scarce. On other hand, the majority of the rice cultivars are adapted to paddy soils and, as an adaptive consequence, commonly they are drought-sensitive [16]. Unfortunately, in the majority of the carried out works, the plants are exposed to acute water deficit, a condition that is commonly associated to drastic stress symptoms [17]. Recently, we demonstrated that rice plants deficient in thylakoidal APX exposed to an acute drought stress triggered increased $\mathrm{H}_{2} \mathrm{O}_{2}$ accumulation which was associated with stomatal closing, evidencing the role of that enzyme in these processes [18].

In this current study, thylakoidal APX knockdown rice plants (apx8) were exposed to mild water deficit to evaluate the role of thylakoidal APX isoform in drought tolerance. To achieve an integrative view, we employed reverse genetic, proteomics and physiological approaches. Our data clearly evidence that silenced rice plants displayed massive changes in protein species expression profile, especially related to redox metabolism and photosynthesis. Remarkably, proteomic analysis suggests that ap $x 8$ knockdown plants are not able to trigger accumulation of essential protein species in suitable levels to effectively cope with drought like the non-transformed plants. These responses suggest that thylakoidal APX protein is essential to phenotypic alterations involving several physiological processes, mainly photosynthetic efficiency and oxidative protection under mild water deficit. The physiological importance of thylakoidal APX isoform in these processes is discussed.

\section{Materials and methods}

\subsection{Construction of the plant vector and plant transformation}

A chimeric gene producing mRNA with a hairpin structure (hpRNA) was constructed based on the sequence of the OsApx8 (LOC_Os02g34810) gene. The following primer pairs were used to amplify a 227 bp RNAiOsApx8 sequence: 5'- CTCGAGGCTGCGAAATA CTCCTACGG-3' and 5'- GGTACCTCGAGAGGAGGTCATCAGACCA TCG-3'. PCR product was cloned into the Gateway vector pANDA, in which hairpin RNA is driven by the maize ubiquitin promotor and an intron placed upstream of the inverted repeats [19]. Rice plants with knockdown of $O s A p x 8$ (apx8 plants) were obtained by Agrobacterium tumefaciens-mediated transformation of rice embryogenic calli (Oryza sativa L. ssp. japonica cv. Nipponbare) induced from seeds and cultivated in NB medium at $28^{\circ} \mathrm{C}$ in the dark [20]. In this work, we used RNAi plants at the $\mathrm{F} 3$ generation.

\subsection{Plant growth and drought stress treatment}

Experiments were taken place at Federal University of Ceará - Brazil ( $\left.3^{\circ} 44^{\prime} 43.6^{\prime \prime S} 38^{\circ} 34^{\prime} 28.3^{\prime \prime} \mathrm{W}\right)$. Non-transformed (NT) and RNAi knockdown rice plants were sowed in a $3 \mathrm{~L}$ vase containing a 1:1 mix of sand and vermiculite. Plants were watered every other day with distilled water, until drainage, and every three days with a half-strength of Hoagland and Arnon's nutrient solution [21]. Plants were grown for 45 days in a greenhouse under natural conditions in a photoperiod of $12 \mathrm{~h}$, as described in Supplementary Table 1 . For the water deficit treatment, the irrigation of plants was withdrawn for four consecutive days. Rice plants daily irrigated as described above were used as the control treatment.

\subsection{Phenotypic parameters}

All phenotypic parameters were determined before and after four days of well-watered control or mild water deficit (drought) exposure in both NT and apx8 plants. Tillers were hand counted and shoot length was measured from the ligule to leaf tip using a flat ruler. To determine shoot biomass, shoots were harvested, oven dried at $80^{\circ} \mathrm{C}$ for $72 \mathrm{~h}$, and weighed according to [22].

\subsection{Relative water content and electrolyte leakage}

The leaf relative water content (RWC) was calculated as follows: $\mathrm{RWC}=[(\mathrm{FW}-\mathrm{DW}) /(\mathrm{TW}-\mathrm{DW})] \times 100$, where $\mathrm{FW}$ is the fresh weight, TW is the turgid weight measured after $6 \mathrm{~h}$ of saturation in deionized water at $4{ }^{\circ} \mathrm{C}$ in the dark and DW is the dry weight determined after $48 \mathrm{~h}$ in an oven at $75^{\circ} \mathrm{C}$ [22]. Cellular integrity (electrolyte leakage) was measured as described previously [23]. Leaf samples were placed in tubes containing deionized water. The flasks were incubated in a shaker for $12 \mathrm{~h}$, and the electric conductivity in the medium (L1) was measured. Then, the medium was boiled $\left(95^{\circ} \mathrm{C}\right)$ for $60 \mathrm{~min}$ and the electric conductivity (L2) was measured again. The relative membrane damage (MD) was estimated by $\mathrm{MD}=\mathrm{L} 1$ / L2 $\times 100$.

\subsection{Quantitative PCR ( $q P C R)$}

Real-time PCR experiments were carried out using cDNA synthesized from total RNA purified with TRIzol (Invitrogen ${ }^{\circledR}$ ). The samples were treated with DNAase (Invitrogen ${ }^{\circledR}$ ) to remove the eventual genomic DNA contamination and complementary DNA (cDNA) was obtained using the SuperscriptTMII (Life Technologies ${ }^{\circledR}$ ) reverse transcriptase system and a 24-polyTV primer (Invitrogen ${ }^{\circledast}$ ). After synthesis, cDNAs were diluted 10-100 times in sterile water for use in PCR reactions. All reactions were repeated four times, and expression data 
analyses were performed after comparative quantification of the amplified products using the $2-\Delta \Delta \mathrm{Ct}$ method [24,25]. qPCR reactions were performed in an Applied Biosystems StepOne plus Real Time PCR system (Applied Bio- systems ${ }^{\oplus}$ ) using SYBR and primer for OsApx8 gene (F-5'-GGTACCTCGAGAGGAGGTCATCAGACCA-3' and R-5'-CTCGAGG CTGCGAAATACTCCTACCG-3'). The following genes were used as normalizers: OsFDH3 (F-5'-TTCCAATGCATTCAAAGCTG-3' and R-5'CAAAATCAGCTGGTGCTTCTC-3'), OsUBI (F-5'- ACCACTTGCACCGCC ACTACT-3' and R-5' - ACGCCTAAGCCTGCTGGTT-3') and OsACT2 (F-5'GGACGTACAACTGGTATCGTGTT-3' and R-5'- GTTCAGCAGTGGTAGT GAAGGAG-3').

\subsection{Assays for APX isoenzyme activities}

Activities of cytosolic (cAPX), stromal (sAPX), thylakoidal (tAPX) and peroxisomal (pAPX) in the leaf extract were separately determined as previously reported by $[26,27]$ utilizing the different sensitivities of these isoenzymes to a low-ASC concentration conditions. Rice leaves were ground to fine powder in liquid $\mathrm{N}_{2}$ and then macerated in $50 \mathrm{mM}$ potassium phosphate buffer ( $\mathrm{pH} 7.0$ ) containing $1 \mathrm{mM}$ ascorbate, $20 \%$ $(w / v)$ sorbitol, $1 \mathrm{mM}$ EDTA, $1 \mathrm{mM}$ phenylmethanesulfonyl fluoride, $40 \mathrm{mM} \mathrm{KCl}, 10 \mathrm{mM} \mathrm{CaCl}_{2}$ and $10 \%$ Glycerol using a mortar and pestle. Thereafter was added $0.1 \% n$-Dodecyl $\beta$-D-maltoside to the homogenate and it was kept under stirring for $15 \mathrm{~min}$ and followed by centrifugation at $3000 \mathrm{x} \mathrm{g}$ for $10 \mathrm{~min}$. The supernatant was centrifuged at $120000 \times \mathrm{g}$ for $20 \mathrm{~min}$ to get the soluble fraction (supernatant) and membrane fraction (pellet). The obtained soluble fraction contained activities of sAPX and cAPX.

The soluble fraction $(10 \mu \mathrm{L})$ was added to $5.0 \mathrm{~mL}$ of $\mathrm{N}_{2}$-bubbling $50 \mathrm{mM}$ potassium phosphate buffer $(\mathrm{pH} 7.0)$ containing $10 \mu \mathrm{M} \mathrm{H}_{2} \mathrm{O}_{2}$. At $3,4,5$, and $6 \mathrm{~min}$ after the start of the incubation, the incubated mixture $(1.98 \mathrm{~mL})$ was sampled and mixed with $10 \mu \mathrm{L}$ of $100 \mathrm{mM}$ ascorbate to terminate the inactivation. The residual oxidizing activity of ascorbate was then assayed by adding $10 \mu \mathrm{L}$ of $10 \mathrm{mM} \mathrm{H}_{2} \mathrm{O}_{2}$. The oxidation of ascorbate was followed by a decrease in the $A_{290 n}$. CAPX and SAPX activities were calculated from the inactivation curve of each isoenzyme. The $120,000 \times \mathrm{g}$ membrane fraction was washed and suspended in $50 \mathrm{mM}$ potassium phosphate buffer ( $\mathrm{pH}$ 7.0) containing $1 \mathrm{mM}$ ascorbate. The suspended-membrane fraction contained activities of tAPX and MAPX isoenzymes, which were assayed separately by the same method using each half-inactivation time as measurements of activities of SAPX and cAPX isoenzymes.

\subsection{Hydrogen peroxide and TBARS content}

Hydrogen peroxide content was measured using the Amplex ${ }^{\circledR}$-red kit (Thermo Fisher Scientific ${ }^{\circledR}$, USA), based on colorimetric measure of resorufin formation in presence of $\mathrm{H}_{2} \mathrm{O}_{2}$ [28]. Fresh leaf samples were macerated with liquid $\mathrm{N}_{2}$ in the presence of $100 \mathrm{mM} \mathrm{K}$-phosphate buffer $\mathrm{pH} 7.5$ and centrifuged at $12,000 \times g\left(4^{\circ} \mathrm{C}\right)$ during $30 \mathrm{~min}$. The supernatant was immediately used for $\mathrm{H}_{2} \mathrm{O}_{2}$ determination. The absorbance at $560 \mathrm{~nm}$ was quantified for $\mathrm{H}_{2} \mathrm{O}_{2}$ measurement. The hydrogen peroxide content was calculated from a standard curve, and the results were expressed as $\eta \mathrm{mol} \mathrm{H}_{2} \mathrm{O}_{2} \mathrm{~g}^{-1}$ fresh mater (FM). Lipid peroxidation was measured based on the formation of thiobarbituric acid- reactive substances (TBARS) in accordance with [29]. The concentration of TBARS was calculated using its absorption coefficient $\left(155 \mathrm{mM}^{-1} \mathrm{~cm}^{-1}\right)$, and the results were expressed as $\eta$ mol MDA-TBA $\mathrm{g}$ $\mathrm{FW}^{-1}$.

\subsection{Gas exchange, chlorophyll a fluorescence and $P_{N}-$ Ci curve}

The net $\mathrm{CO}_{2}$ assimilation rate $\left(P_{N}\right)$, transpiration $(E)$, stomatal conductance $\left(g_{S}\right)$ and intercellular $\mathrm{CO}_{2}$ partial pressure $(\mathrm{Ci})$ were measured using a portable infra-red gas analyzer system, equipped with an LED source and a leaf chamber (IRGA LI-6400XT, LI-COR, Lincoln,
NE, USA). For instantaneous measurements, the PPFD was fixed at $1200 \mu \mathrm{mol} \mathrm{m}^{-2} \mathrm{~s}^{-1}$, temperature equaled to $28^{\circ} \mathrm{C}$, VDP between 1.0 and $1.5 \mathrm{kPa}$, and external $\mathrm{CO}_{2}$ was fixed at atmospheric partial pressure (38 Pa). The amount of blue light was set to be $10 \%$ of the PPFD to maximize stomatal aperture [30]. Also, the $P_{N}$ was measured in response to changes in the intercellular $\mathrm{Ci}$ controlled inside the IRGA leaf chamber. A-Ci fitting curves were determined according to models proposed by [31]. The following parameters associated with photosynthetic efficiency were determined: maximum Rubisco carboxylation rate (Vcmax), maximum rate of photosynthetic electron transport (Jmax), maximum net photosynthesis $\left(P_{N} \max \right)$ and mesophyll conductance $(\mathrm{gm})$. Photorespiratory rate $\left(\mathrm{P}_{\mathrm{R}}\right)$ was obtained accorded to [32].

In vivo chlorophyll $a$ fluorescence was measured using a LI-6400-40 Leaf Chamber Fluorometer (LI-COR, Lincoln, NE, USA) coupled with the IRGA. The actinic light utilized for measuring the gas exchange and chlorophyll $a$ fluorescence was $1000 \mu \mathrm{mol} \mathrm{m}^{-2} \mathrm{~s}^{-1}$ PPFD, which corresponded to the saturation light for $\mathrm{CO}_{2}$ assimilation in rice [12]. The fluorescence parameters were measured using the saturation pulse method [33] in leaves exposed to light or $30 \mathrm{~min}$ dark-acclimated conditions. The intensity and duration of the saturation light pulse were $8000 \mu \mathrm{mol} \mathrm{m}^{-2} \mathrm{~s}^{-1}$ and $0.7 \mathrm{~s}$, respectively. The following parameters were assessed: the maximum quantum yield of PSII [Fv/ $\mathrm{Fm}=(\mathrm{Fm}-\mathrm{Fo}) / \mathrm{Fm}]$, measured in 30-min dark-adapted leaves, and the effective quantum yield of PSII $\left[\Delta \mathrm{F} / \mathrm{Fm}{ }^{\prime}=\left(\mathrm{Fm}^{\prime}-\mathrm{Fs}\right) / \mathrm{Fm}^{\prime}\right]$, measured in leaves exposed to actinic light of $1000 \mu \mathrm{mol} \mathrm{m}^{-2} \mathrm{~s}^{-1}$.

\subsection{Protein extraction for proteomic analysis}

Leaf samples (500 mg) were ground using a mortar and pestle with liquid $\mathrm{N}_{2}$. Samples were lyophilized and the samples were added to $10 \%$ trichloroacetic acid and $0.07 \%$ 2-mercaptoethanol solution in acetone $(v / v)$ and mixed thoroughly by vortex. The mixture was sonicated for $10 \mathrm{~min}$ and incubated for $1 \mathrm{~h}$ at $-20^{\circ} \mathrm{C}$. Afterwards, centrifuged at $9000 \times g$ for $20 \mathrm{~min}$ at $4^{\circ} \mathrm{C}$, the supernatant was removed, and the remaining pellet was washed twice with $0.07 \% 2$-mercaptoethanol in acetone $(\mathrm{v} / \mathrm{v})$. The pellet was dried using a Speed-Vac concentrator (Savant Instruments, Hicksville, NY, USA) and resuspended in a lysis buffer containing $8 \mathrm{M}$ urea, $2 \mathrm{M}$ thiourea, $5 \%$ CHAPS, and $2 \mathrm{mM}$ tributylphosphine and homogenized by vigorous vortex for $1 \mathrm{~h}$ at $25^{\circ} \mathrm{C}$. The suspension was centrifuged at $20,000 \mathrm{x} \mathrm{g}$ for $20 \mathrm{~min}$ at $25^{\circ} \mathrm{C}$ and the resulting supernatant, protein extract, was collected. Protein concentration was determined using Bradford method [34] with BSA as a standard.

\subsection{Protein purification, digestion, and desalt for proteomic analysis}

Extracted proteins $(100 \mu \mathrm{g})$ were adjusted to final volume of $100 \mu \mathrm{L}$. The samples were enriched with methanol and chloroform to remove detergent from samples, using standard procedures [35]. Briefly, $400 \mu \mathrm{L}$ of methanol was added to samples and mixed. Chloroform $(100 \mu \mathrm{L})$ and $300 \mu \mathrm{L}$ of water were added to samples, mixed, and centrifuged at $20,000 \times g$ for $10 \mathrm{~min}$ to achieve phase separation. The upper phase was discarded and $300 \mu \mathrm{L}$ of methanol was added to lower phase. Samples were centrifuged at $20,000 \times g$ for $10 \mathrm{~min}$ and the pellet was dried. Dried samples were reduced with $25 \mathrm{mM}$ dithiothreitol for $30 \mathrm{~min}$ at $56^{\circ} \mathrm{C}$ in dark and alkylated with $30 \mathrm{mM}$ idoacetamide for $30 \mathrm{~min}$ at $37^{\circ} \mathrm{C}$ in dark. Alkylated proteins were digested with trypsin and lysyl endopeptidase (Wako, Osaka, Japan) at 1:100 enzyme/protein ratio at $37^{\circ} \mathrm{C}$ for $16 \mathrm{~h}$ in dark. Peptides were acidified with $20 \%$ formic acid $(\mathrm{pH}<3)$ and desalted with a C18-pipette tip (Nikkyo Technos, Tokyo, Japan). 


\subsection{Protein species identification using nanoliquid chromatography mass spectrometry}

The peptide samples were separated using an Ultimate 3000 nanoLC system (Dionex, Germering, Germany), and the peptide ions were detected using a nanospray LTQ Orbitrap Discovery MS (Thermo Fisher Scientific, San Jose, CA, USA) with data-dependent acquisition mode with installed Xcalibur software (version 2.1, Thermo Fisher Scientific). The peptide samples were loaded onto a C18 PepMap trap column ( $300 \mu \mathrm{m}$ ID $\times 5 \mathrm{~mm}$, Thermo Fisher Scientific) equilibrated with $0.1 \%$ formic acid and eluted from the trap column with a linear acetonitrile gradient in $0.1 \%$ formic acid at a flow rate of $200 \eta \mathrm{L} / \mathrm{min}$. The eluted peptides were loaded and separated on a C18 capillary tip column (75 $\mu \mathrm{m}$ ID $\times 120 \mathrm{~mm}$, Nikkyo Technos) with a spray voltage of $1.5 \mathrm{kV}$. Full-scan mass spectra were acquired in the Orbitrap MS over $400-1500 \mathrm{~m} / \mathrm{z}$ with a resolution of 30,000 . The top ten most intense precursor ions were selected for collision-induced fragmentation in the linear ion trap at normalized collision energy of 35\%. Dynamic exclusion was employed within 90 s to prevent the repetitive selection of peptides [36].

\subsection{Data acquisition by mass spectrometry analysis}

Protein species identification was performed using the Mascot search engine (version 2.5.1, Matrix Science, London, U.K.) and a rice protein database $(50,253$ sequences and 15,266,515 residues) obtained from the Rice Annotation Project Database (RAP-DB, http://rapdb.dna. affrc.go.jp), including protein sequences supported by FL-cDNA and EST data (IRGSP-1.0_protein_20134-24) and protein sequence predicted computationally (IRGSP1.0_predicted protein_2013-3-9). Proteome Discoverer software (version 1.4, Thermo Fisher Scientific) was used to process the acquired raw data files. For the Mascot searches, the carbamethylation of cysteine was set as a fixed modification and oxidation of methionine was set as a variable modification. Trypsin was specified as the proteolytic enzyme and one missed cleavage was allowed. Peptide mass tolerance was set at $10 \mathrm{ppm}$, fragment mass tolerance was set at $0.5 \mathrm{Da}$, the peptide charge was set at $+2,+3$, and +4 . An automatic decoy database search was performed a part of the search. Mascot results were filtered with the Percolator function to improve the accuracy and sensitivity of peptide identification. The acquired Mascot results were imported to SIEVE software (version 2.1, Thermo Fisher Scientific).

\subsection{Differential analysis of proteins using mass spectrometry data}

For the differential analysis of relative abundances of peptides and protein species between samples the commercial label-free quantification package SIEVE was used. The chromatographic peaks detected by MS were aligned, and the peptide peaks were detected as a frame on all parent ions scanned by MS/MS using $5 \mathrm{~min}$ of frame time width and $10 \mathrm{ppm}$ of frame $\mathrm{m} / \mathrm{z}$ width. Chromatographic peak areas within a frame were compared for each sample, and the ratios between samples in a frame were determined. The frames detected in the MS/MS scan were matched to the imported Mascot results. The peptide ratio between samples was determined from the variance-weighted average of the ratios in frames that matched the peptides in the MS/MS spectrum. The ratios of peptides were further integrated to determine the ratio of the corresponding protein species. In the differential analysis of protein species abundance, total ion current was used for normalization. The minimum requirement for identification of a protein species was two matched peptides. Significant differences between abundance of each protein species were analyzed by Student's $t$-test $(p \leq .05)$. The average test was performed between the ratios of the values obtained from each treatment and NT-control plants.

\subsection{Principal component analysis}

In order to synthesize the large number of variables evaluated in the current proteomic study, a principal component analysis (PCA) was performed employing normalized ratios of protein species from the different treatments (APX8C, NTD and APX8D) all compared with NTC as reference (see Supplementary Table 3). The PCA was performed employing the OriginPro 2017 software (Origin Lab Corporation, Northampton, USA), according to the software user guide.

\subsection{Functional analysis}

Functional analysis of identified protein species was performed using MapMan (http://mapman.gabipd.org/) [37].

\subsection{Statistical analyses and experimental design}

The experiment was arranged in a completely randomized design in a $2 \times 2$ factorial: two genotypes (NT and $a p \times 8$ ) and two treatments (control and drought), with four independent replicates. An individual pot containing 2 plants represented each replicate. Physiological data were analyzed using ANOVA, and the means were compared using the Tukey's test $(p \leq 0.05)$. Proteomics data were tested by Student's $t$-test $(p \leq 0.05)$.

\section{Results and discussion}

\subsection{OsApx8 silencing decreases strongly OsApx8 gene expression, APX8} protein abundance and APX8 activity under well-watered condition

In order to determine the physiological role of rice thylakoidal APX under well-watered and mild drought conditions, RNAi-knockdown plants were obtained (Supplementary Fig. 1). Silenced rice plants displayed a slight decrease in shoot biomass, number of tillers and shoot length compared to NT plants in well-watered conditions (Supplementary Table 2). Our group has previously reported that double silencing of chloroplast isoforms (OsApx7 and OsApx8) did not display phenotype differences in rice plants grown under optimal conditions, despite the expression of both genes have been greatly reduced [11]. In this study, RNAi-knockdown caused a strong decrease of OsApx8 transcript amount (by 90\%) in apx8 plants (Supplementary Fig. 2). Proteomic analysis corroborated these results evidencing that APX8 protein amount in silenced plants represented only $6 \%$ of NT (Table 1). This decrease was associated to a significant reduction in APX activity in the thylakoidal fraction that reached approximately $60 \%$ when compared to NT plants (Fig. 1). Unexpectedly, OsApx8 silencing also negatively affected the activities of cytosolic (cAPX), peroxisomal (pAPX) and stromal (sAPX) isoforms, reducing by approximately 88, 15 and $23 \%$ respectively, compared to NT plants, (Fig. 1). The reduction in the activities of these APX isoforms could have contributed for the slight increase noticed in the $\mathrm{H}_{2} \mathrm{O}_{2}$ content of silenced plants (Fig. 2A).

\subsection{Silenced plants accumulate $\mathrm{H}_{2} \mathrm{O}_{2}$ in both control and mild drought} stress conditions and exhibit higher TBARS content and membrane damage

In order to investigate the effects of OsApx8 silencing and water deficit on redox homeostasis, we evaluated the level of oxidative stress markers $\left(\mathrm{H}_{2} \mathrm{O}_{2}\right.$ content, TBARS content - an indicative of lipid peroxidation and membrane damage - by electrolyte leakage measurement), in both silenced and NT plants. In parallel to reduction in the activities of thylakoidal APX and other APX isoforms, the water deficit induced increases in the contents of $\mathrm{H}_{2} \mathrm{O}_{2}$ and TBARS in apx8 plants that were related to increase in membrane damage, compared with NT plants (Fig. 2 and Supplementary Table 2). These results indicate that silenced rice plants suffered higher redox disturbances, evidencing the importance of thylakoidal APX as a $\mathrm{H}_{2} \mathrm{O}_{2}$ scavenger in chloroplasts 
Table 1

Summary of significantly changed proteins of NT and apx 8 rice plants exposed to control or drought stress for 4 days. Significant differences between abundance of each protein were analyzed by Student's t-test $(p \leq 0.05)$. The average test was performed between the ratios of the values obtained from each treatment and NTcontrol plants.

\begin{tabular}{|c|c|c|c|c|c|c|c|c|c|}
\hline GO & Acession & $\mathrm{N}^{\circ}$ & Protein name & p-value & NT-D x NT-C & p-value & $\begin{array}{l}\text { apx8-D x NT- } \\
\text { C }\end{array}$ & p-value & $\begin{array}{l}\text { apx8-C x NT- } \\
\text { C }\end{array}$ \\
\hline \multirow[t]{26}{*}{ PS } & Os02t0197600 & 1 & Chlorophyll a/b binding protein type III & 0.01 & 26.40 & 0.00 & 20.63 & 0.04 & 2.40 \\
\hline & Os01t0600900 & 2 & Chlorophyll a/b binding protein LHCP & 0.00 & 2.90 & 0.00 & 0.89 & 0.01 & 2.43 \\
\hline & Os03t0592500 & 3 & Chlorophyll a/b binding protein type II & 0.00 & 114.13 & 0.00 & 35.35 & 0.00 & 27.87 \\
\hline & Os07t0558400 & 4 & Chlorophyll a/b binding protein CP29 & 0.00 & 97.42 & 0.00 & 7.07 & 0.00 & 25.31 \\
\hline & Os01t0869800 & 5 & PsbS & 0.00 & 25.15 & 0.00 & 7.41 & 0.01 & 3.72 \\
\hline & Os07t0141400 & 6 & PsbP & 0.00 & 8.31 & 0.00 & 7.49 & 0.00 & ND \\
\hline & Os07t0435300 & 7 & Photosystem I reaction center subunit IV & 0.00 & 505.73 & 0.00 & 20.66 & 0.00 & ND \\
\hline & Os07t0556200 & 8 & Cytochrome b6-f complex & 0.01 & 49.00 & 0.00 & 3.54 & 0.00 & ND \\
\hline & Os02t0103800 & 9 & Ferredoxin NADP reductase (FNR) & 0.00 & 32.53 & 0.00 & 7.80 & 0.00 & ND \\
\hline & Os06t0101600 & 10 & Plastocyanin & 0.00 & 1.64 & 0.00 & 2.74 & 0.00 & ND \\
\hline & Os10t0355800 & 11 & ATP synthase CF1 beta subunit. & 0.00 & 16.35 & 0.00 & 7.43 & 0.00 & ND \\
\hline & Os07t0513000 & 12 & ATP synthase gamma chain & 0.00 & 9.48 & 0.00 & 3.96 & 0.00 & 0.91 \\
\hline & Os01t0682500 & 13 & D-glycerate 3-kinase & 0.00 & 3.53 & 0.00 & 0.81 & 0.01 & 2.26 \\
\hline & Os06t0611900 & 14 & Glycine decarboxylase P subunit & 0.00 & 7.34 & 0.00 & 45.97 & 0.00 & 7.99 \\
\hline & Os01t0711400 & 15 & Glycine dehydrogenase $\mathrm{P}$ protein & 0.00 & 8.08 & 0.00 & 58.27 & 0.00 & 8.29 \\
\hline & Os07t0152900 & 16 & Glycolate oxidase & 0.00 & 9.97 & 0.00 & 7.82 & 0.01 & 8.30 \\
\hline & Os03t0738400 & 17 & Serine hydroxymethyltransferase & 0.00 & 33.22 & 0.00 & 4.05 & 0.00 & 20.10 \\
\hline & Os12t0207600 & 18 & Rubisco large subunit & 0.00 & 382.39 & 0.00 & 707.89 & 0.00 & 92.69 \\
\hline & Os06t0133800 & 19 & Transketolase & 0.00 & 11.32 & 0.00 & 5.59 & 0.00 & 6.40 \\
\hline & Os02t0698000 & 20 & Phosphoribulokinase & 0.00 & 54.03 & 0.00 & 60.22 & 0.00 & 5.56 \\
\hline & Os09t0535000 & 21 & Triosephosphate isomerase & 0.00 & 0.50 & 0.01 & 0.30 & 0.00 & ND \\
\hline & Os01t0905800 & 22 & Aldolase & 0.00 & 25.66 & 0.00 & 2.40 & 0.00 & ND \\
\hline & Os11t0171300 & 23 & Fructose bisphosphate aldolase & 0.00 & 9.78 & 0.00 & 2.70 & 0.00 & 0.84 \\
\hline & Os04t0234600 & 24 & Sedoheptulose-1,7-bisphosphatase & 0.00 & 8.53 & 0.00 & 0.30 & 0.00 & ND \\
\hline & Os11t0707000 & 25 & Ribulose bisphosphate carboxylase activase & 0.00 & 87.87 & 0.00 & 89.50 & 0.00 & 27.01 \\
\hline & Os01t0882500 & 26 & NADH dehydrogenase I & 0.03 & 29.52 & 0.00 & 46.00 & 0.00 & ND \\
\hline \multirow[t]{5}{*}{ Stress } & Os06t0197550 & 27 & Heat shock protein 10 & 0.00 & 5.76 & 0.01 & 6.84 & 0.00 & ND \\
\hline & Os01t0840100 & 28 & Heat shock protein 70 & 0.00 & 3.47 & 0.00 & 5.00 & 0.03 & 0.00 \\
\hline & Os12t0244100 & 29 & Heat shock protein 70 & 0.00 & 1.62 & 0.00 & 3.69 & 0.01 & 0.43 \\
\hline & Os06t0716700 & 30 & Heat shock protein 90 & 0.03 & 0.52 & 0.00 & 2.68 & 0.02 & 0.46 \\
\hline & Os09t0474300 & 31 & Heat shock protein 90 & 0.00 & 1.56 & 0.00 & 2.10 & 0.03 & 0.05 \\
\hline Redox & Os11t0199200 & 32 & Protein disulfide isomerase & 0.01 & 12.65 & 0.00 & 0.97 & 0.01 & 0.54 \\
\hline Signaling & Os04t0402100 & 33 & Calnexin & 0.01 & 10.08 & 0.01 & 2.36 & 0.00 & ND \\
\hline DNA & Os06t0701100 & 34 & Eukaryotic initiation factor $4 \mathrm{~A}$ & 0.00 & 6.48 & 0.00 & 2.70 & 0.03 & 0.60 \\
\hline \multirow[t]{14}{*}{ Protein } & Os12t0507200 & 35 & Eukaryotic translation initiation factor $5 \mathrm{~A}$ & 0.00 & 1.76 & 0.00 & 2.67 & 0.00 & ND \\
\hline & Os03t0577000 & 36 & Ribosomal protein S3 & 0.00 & 2.56 & 0.00 & 0.09 & 0.01 & 0.79 \\
\hline & Os11t0482000 & 37 & 40S ribosomal protein S5. & 0.00 & 11.43 & 0.00 & 7.74 & 0.00 & ND \\
\hline & Os05t0388500 & 38 & 50 S ribosomal protein $\mathrm{L} 1$. & 0.00 & 11.60 & 0.05 & 0.73 & 0.00 & ND \\
\hline & Os05t0568300 & 39 & 50S ribosomal protein L12 & 0.00 & 17.94 & 0.00 & 0.88 & 0.00 & ND \\
\hline & Os04t0538100 & 40 & Elongation factor $\mathrm{G}$ & 0.00 & 3.44 & 0.00 & 2.37 & 0.04 & 0.05 \\
\hline & Os02t0519900 & 41 & Elongation factor EF-2 & 0.00 & 4.15 & 0.00 & 0.90 & 0.04 & 2.40 \\
\hline & Os04t0118400 & 42 & Elongation factor EF-2 & 0.00 & 4.18 & 0.00 & 0.90 & 0.04 & 2.40 \\
\hline & Os07t0662500 & 43 & Elongation factor 1-beta & 0.00 & 5.59 & 0.00 & 4.54 & 0.00 & ND \\
\hline & Os02t0595700 & 44 & $\begin{array}{l}\text { Chloroplast translational elongation factor } \\
\mathrm{Tu}\end{array}$ & 0.00 & 26.33 & 0.00 & 57.42 & 0.01 & 6.23 \\
\hline & Os05t0373700 & 45 & Nascent polypeptide associated complex & 0.00 & 26.54 & 0.00 & 2.86 & 0.00 & ND \\
\hline & Os12t0624000 & 46 & Methionine synthase protein & 0.00 & 3.34 & 0.00 & 5.27 & 0.02 & 0.05 \\
\hline & Os01t0323600 & 47 & S-adenosylmethionine synthase 2 & 0.00 & 1.90 & 0.00 & 3.09 & 0.00 & ND \\
\hline & Os05t0135700 & 48 & S-adenosylmethionine synthetase 1 & 0.00 & 1.89 & 0.00 & 3.07 & 0.00 & ND \\
\hline $\begin{array}{l}\text { Hormone and polyamine } \\
\text { synthesis }\end{array}$ & Os07t0408700 & 49 & Spermidine synthase 2 & 0.00 & ND & 0.03 & 9.47 & 0.00 & ND \\
\hline \multirow[t]{12}{*}{ Carbohydrate metabolism } & Os06t0136600 & 50 & Enolase 1 & 0.00 & 8.46 & 0.00 & 6.48 & 0.03 & 3.62 \\
\hline & Os10t0167300 & 51 & Enolase 2 & 0.00 & 14.94 & 0.00 & 6.61 & 0.00 & ND \\
\hline & Os04t0677500 & 52 & Pyruvate kinase & 0.01 & 5.20 & 0.00 & 2.58 & 0.01 & 0.58 \\
\hline & Os05t0522500 & 53 & Hexokinase 1 & 0.03 & 2.13 & 0.00 & ND & 0.00 & ND \\
\hline & Os01t0742500 & 54 & Hexokinase & 0.00 & ND & 0.01 & 0.30 & 0.01 & 0.61 \\
\hline & Os06t0256500 & 55 & Glucose-6-phosphate isomerase & 0.00 & 1.85 & 0.00 & 2.28 & 0.00 & ND \\
\hline & Os04t0486600 & 56 & Glyceraldehyde-3-phosphate dehydrogenase & 0.00 & 20.75 & 0.00 & 30.61 & 0.00 & ND \\
\hline & Os03t0712700 & 57 & Phosphoglucomutase & 0.00 & 1.63 & 0.00 & 2.35 & 0.02 & 0.98 \\
\hline & Os01t0639900 & 58 & Carbonic anhydrase & 0.00 & 18.46 & 0.00 & 4.34 & 0.01 & 2.04 \\
\hline & Os02t0739600 & 59 & Pyruvate dehydrogenase E1 & 0.00 & 16.60 & 0.00 & 3.30 & 0.00 & ND \\
\hline & Os09t0509200 & 60 & Pyruvate dehydrogenase E1 beta & 0.00 & 3.85 & 0.01 & 0.30 & 0.00 & ND \\
\hline & Os07t0410100 & 61 & Dihydrolipoamide $S$-acetyltransferase & 0.02 & 3.11 & 0.00 & ND & 0.00 & ND \\
\hline
\end{tabular}

(continued on next page) 
Table 1 (continued)

\begin{tabular}{|c|c|c|c|c|c|c|c|c|c|}
\hline GO & Acession & $\mathrm{N}^{\circ}$ & Protein name & p-value & NT-D x NT-C & p-value & $\begin{array}{l}\text { apx8-D x NT- } \\
\text { C }\end{array}$ & $p$-value & $\begin{array}{l}\text { apx8-C x NT- } \\
\text { C }\end{array}$ \\
\hline \multirow[t]{18}{*}{ Redox } & Os02t0553200 & 62 & Thylakoid bound ascorbate peroxidase & 0.00 & 4.96 & 0.00 & 0.60 & 0.00 & 0.06 \\
\hline & Os07t0694700 & 63 & Ascorbate peroxidase 2 & 0.00 & 10.92 & 0.00 & 4.05 & 0.00 & ND \\
\hline & Os08t0549100 & 64 & Peroxisome type ascorbate peroxidase & 0.00 & 0.84 & 0.00 & 0.80 & 0.00 & 0.70 \\
\hline & Os06t0232600 & 65 & Dehydroascorbate reductase. & 0.00 & 12.70 & 0.03 & 0.20 & 0.02 & 0.26 \\
\hline & Os02t0813500 & 66 & Glutathione reductase & 0.00 & 3.08 & 0.00 & 2.26 & 0.01 & 0.50 \\
\hline & Os07t0462000 & 67 & Glutamate cysteine ligase & 0.00 & 1.08 & 0.00 & ND & 0.01 & 0.81 \\
\hline & Os01t0675100 & 68 & Peroxiredoxin-2C & 0.00 & 6.03 & 0.00 & 6.81 & 0.04 & 4.73 \\
\hline & Os02t0192700 & 69 & Peroxiredoxin-2E-2 & 0.00 & 14.95 & 0.00 & 7.37 & 0.00 & 2.98 \\
\hline & Os02t0537700 & 70 & 2-cys peroxiredoxin BAS1 & 0.00 & 28.63 & 0.00 & 2.75 & 0.05 & 3.96 \\
\hline & Os02t0115700 & 71 & Catalase isozyme A & 0.00 & 0.75 & 0.00 & 0.90 & 0.04 & 2.21 \\
\hline & Os06t0727200 & 72 & Catalase isozyme B & 0.00 & 20.09 & 0.00 & 0.45 & 0.03 & 28.00 \\
\hline & Os03t0131200 & 73 & Catalase isoenzyme C & 0.00 & 9.62 & 0.00 & 0.71 & 0.01 & 2.43 \\
\hline & Os05t0323900 & 74 & Superoxide dismutase $\mathrm{Mn}$ & 0.00 & 9.92 & 0.00 & 3.64 & 0.01 & 0.83 \\
\hline & Os09t0567300 & 75 & Monodehydroascorbate reductase & 0.00 & 5.01 & 0.00 & 2.55 & 0.00 & ND \\
\hline & Os06t0196300 & 76 & Peroxiredoxin Q & 0.02 & 3.91 & 0.00 & 2.89 & 0.00 & ND \\
\hline & Os01t0913000 & 77 & Thioredoxin F & 0.01 & 3.65 & 0.01 & 3.61 & 0.00 & ND \\
\hline & Os08t0561700 & 78 & Superoxide dismutase $\mathrm{Cu}-\mathrm{Zn}$ & 0.00 & 1001.10 & 0.00 & 40.69 & 0.00 & ND \\
\hline & Os12t0188700 & 79 & Thioredoxin M5 & 0.00 & 78.74 & 0.01 & 0.78 & 0.02 & 5.23 \\
\hline
\end{tabular}

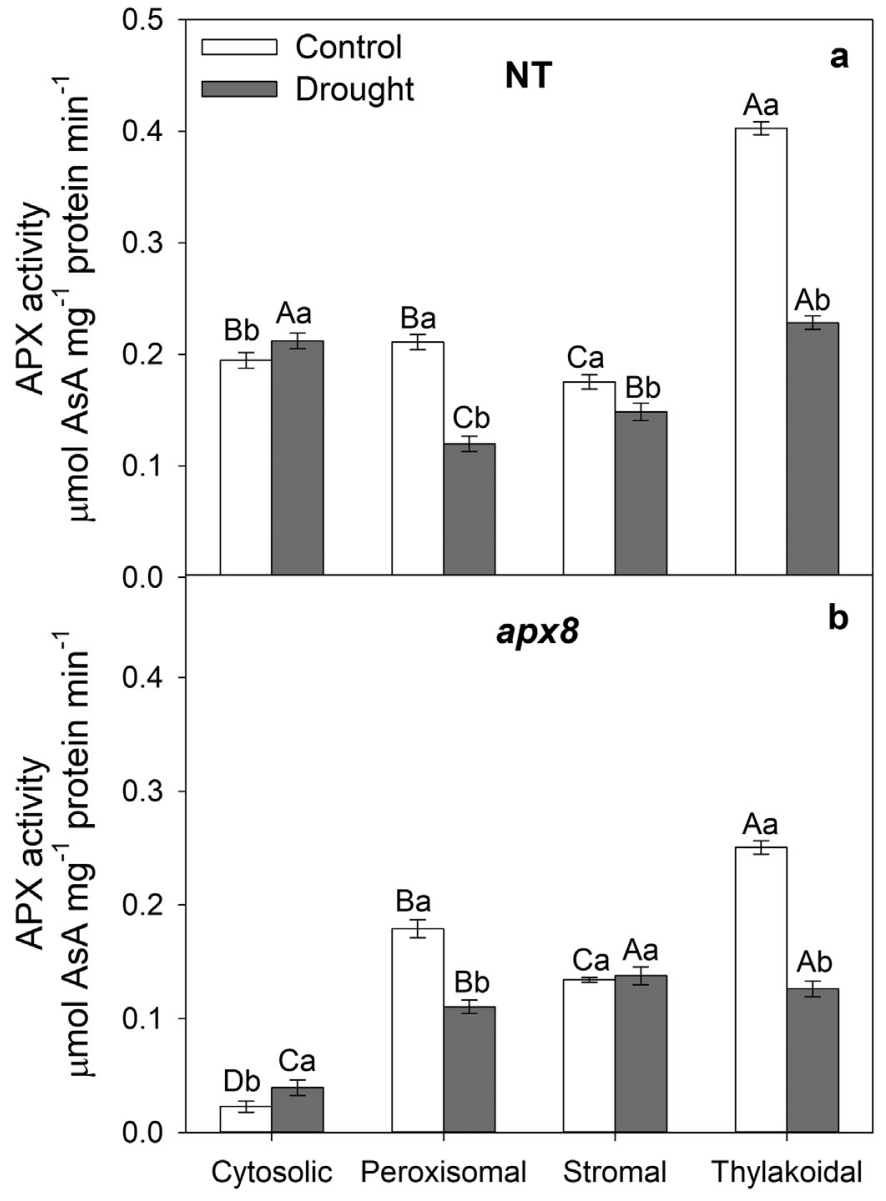

Fig. 1. Ascorbate peroxidase activity in cytosolic, stromal, thylakoidal and peroxisomal fractions measured in leaves of rice plants exposed to control (a) or 4 days of drought stress (b). Different capital letters represent significant differences between the treatments within genotypes (NT and apx8), and different lowercase letters represent significant differences between the genotypes within treatments (control and drought). Data are means of four replicates and the averages were compared using the Tukey's test, $(p \leq 0.05)$.

$[10,38]$. We have previously showed that rice plants knocked down for both chlAPXs (apx7/8) also exhibit higher levels of $\mathrm{H}_{2} \mathrm{O}_{2}$, membrane damage and TBARS content, than NT plants, in both control conditions and after oxidative stress induced by methyl viologen [11]. Since $\mathrm{H}_{2} \mathrm{O}_{2}$

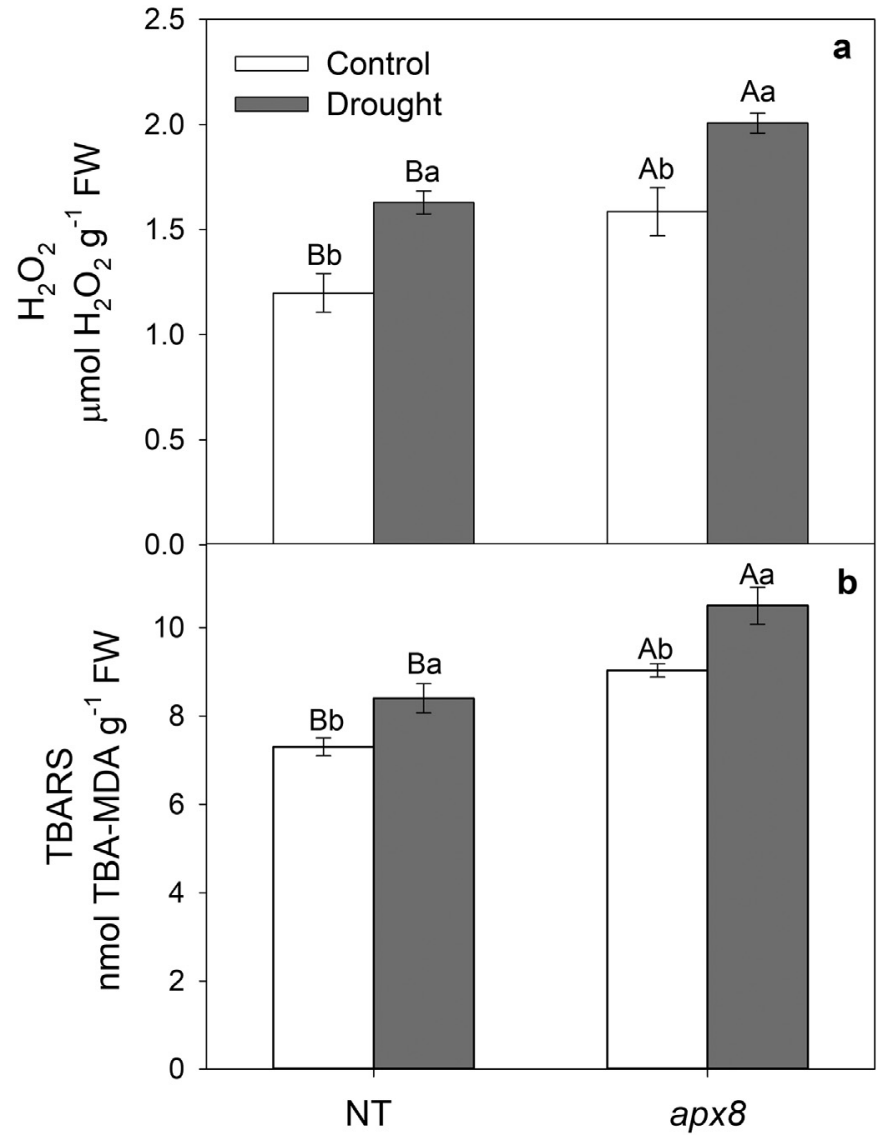

Fig. 2. $\mathrm{H}_{2} \mathrm{O}_{2}$ (a) and thiobarbituric acid-reactive-substances, TBARS (b) contents of NT and apx8 rice plants exposed to control or drought stress for 4 days. Different capital letters represent significant differences between the treatments within genotypes (NT and apx8), and different lowercase letters represent significant differences between the genotypes within treatments (control and drought). Data are means of four replicates and the averages were compared using the Tukey's test, ( $p \leq 0.05)$.

steady-state concentration is increased in apx8 plants, it is plausible to argue that this ROS could act as a signal involved in the oxidative response network in conditions of thylakoidal APX deficiency, as has been previously demonstrated for cytosolic APXs-knockdown rice [13] and in several other plant species [8-10,39]. 
Much have been discussed in the literature about the function of $\mathrm{H}_{2} \mathrm{O}_{2}$ as a signaling molecule in plants and it has been speculated that this ROS could act through the oxidation of cysteine residues in redoxsensitive proteins, such as the catalytic center of the thiol peroxidases [40]. Altogether, the obtained data indicate that apx8 rice plants showed markedly changes in their redox homeostasis in normal growth conditions and these changes could have led to distinct sensitive responses when they are exposed to mild drought stress compared to NT plants.

\subsection{Proteomic analysis evidences that silenced plants display a great} number of decreased protein species and after drought exposure the intensity and amount of increased protein species are restricted compared to NT plants

In this study, 1065 protein species had its abundance significantly changed $(p \leq 0.05)$ in APX8-control, NT-D and APX-D, compared to NT-control plants (Supplementary Table 3). Among these, 298 protein species were identified in apx8 plants exposed to control (90 increased and 208 decreased), 754 protein species in NT plants exposed to drought stress (662 increased and 92 decreased) and 809 in apx8 plants exposed to drought stress (511 increased and 296 decreased) (Fig. 3). We also performed a principal component analysis (PCA) in order to reduce the large number of variables to a smaller number of groups that can be more readily visualized and interpreted. The PCA was performed employing normalized protein species ratios, with NT- control (NT-C) as a reference (value 1.0) and the principal components 1 and 2 were able to explain $71.73 \%$ of the variance. The loading plot based on PCA results evidenced that the changes in protein species ratios presented by drought stress NT plants (NT-D) were distinct from $a p \times 8$ control (APX8C) and $a p x 8$ drought stressed plants (APX8-D) - (Fig. 4). These responses indicate that drought treatment was able to induce stronger changes in the proteomic profile in NT plants as compared to apx 8 silenced ones. A possible explanation for these interesting results consists in the fact that changes induced by APX8 silencing in rice plants could be able to produce a pre-acclimation condition to abiotic stress [18]. Accordingly, the initial changes in apx8 plants should result in a reduced plasticity of proteomic profile when a second stress situation was imposed, which was already observed in other studies involving apx gene family silencing in rice [11-13].

Based on MapMan ontology, all significantly changed protein species were separated into 19 functional categories: C1 metabolism, cell, DNA, hormone and polyamine metabolism, carbohydrate metabolism, lipid metabolism, miscellaneous enzyme family, mitochondrial electron transport, unassigned protein species, protein metabolism, nucleotide metabolism, photosynthesis (PS), RNA, redox, secondary metabolism, signaling, stress, tetrapyrrole synthesis and transport (Fig. 5). Under

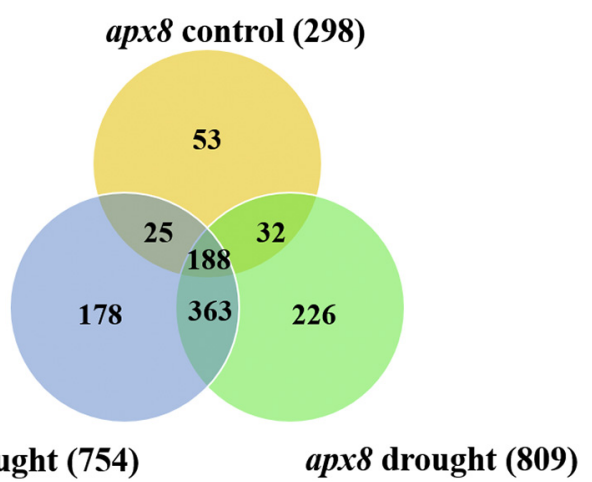

Fig. 3. Venn diagram depicting protein species of NT and apx 8 rice leaves after control or 4 days of drought stress. The Venn diagram was constructed in the Pangloss Venn diagram generator (http://www.pangloss.com/seidel/ Protocols/venn.cgi).

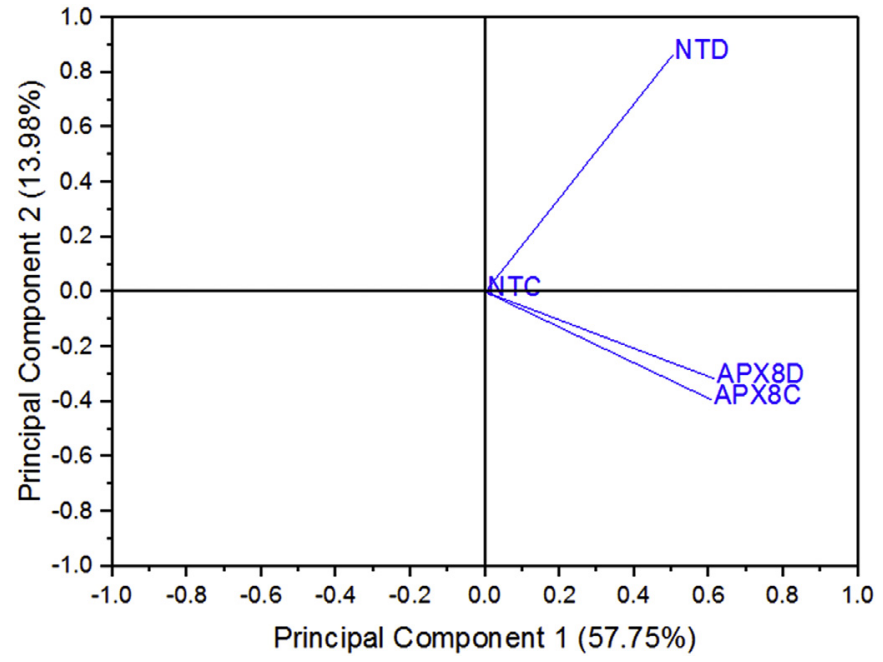

Fig. 4. Loading plot based on the principal component analysis (PCA) results from proteomic changes of data of rice NT and apx8 leaves subjected to control (NTC and APX8C, respectively) and 4 days of drought stress (NTD and APX8D, respectively). The PCA was performed employing normalized protein species ratios, based on NTC abundance levels as reference. The principal components (PC) 1 and 2 explain $71.73 \%$ of the variance.

control conditions, apx8 plants only exhibited $29.5 \%$ of increased protein species in total, and maintained "carbohydrate metabolism", "signaling", "stress" and "transport" categories strongly decreased. After drought stress, most of protein species were increased in both genotypes, especially in NT $(87.8 \%)$ in comparison to apx8 plants (63.3\%), suggesting a substantial number of drought-responsive protein species in rice plants (Fig. 5, Table 1).

In both genotypes, the major increased protein species categories were the "carbohydrate" and "protein metabolism" but the number of these increased protein species was much higher in NT plants. Both categories are considered key-processes involved in stress response, once they support the cellular energy costs required to trigger effective plant defense responses and provide specific molecular mediators in many plant cell processes [41]. In contrast, ap $x 8$ plants showed higher number of decreased protein species than NT plants, in all categories, and a strong increase in the quantity of protein species classified in "stress" category, after the drought treatment. These results suggest that apx 8 plants could have triggered a different pattern of protein regulation in response to drought stress after silencing, in comparison to NT plants, as is corroborated by PCA (Fig. 4). That differential metabolic reprogramming in silenced plants could be a consequence of a previous increased $\mathrm{H}_{2} \mathrm{O}_{2}$ steady state level and/or other redox alterations [42]. Thus, these distinct responses highlight the great physiological importance of thylakoidal APX, especially in the maintaining of the redox balance, possibly affecting several metabolic pathways by $\mathrm{H}_{2} \mathrm{O}_{2}$ signaling.

3.4. In vivo gas exchange measurements indicate that silenced plants are more sensitive to drought compared to NT but they display similar photochemical activity

In order to investigate differences in the photosynthetic capacity, gas exchanges and photochemical measurements were performed in well-watered and drought conditions. In non-stressful conditions, both silenced and NT plants displayed similar photosynthetic perfomance. However, under mild water deficit the apx8 plant presented higher diffusive limitations indicated by higher reduction in stomatal conductance $\left(\mathrm{g}_{\mathrm{S}}\right)$, which was related to decreases in net $\mathrm{CO}_{2}$ assimilation $\left(\mathrm{P}_{\mathrm{N}}\right)$, intercellular $\mathrm{CO}_{2}$ concentration (Ci) and transpiration (E) - Fig. 6 . These changes were associated with higher decreases of in vivo 
DECREASE

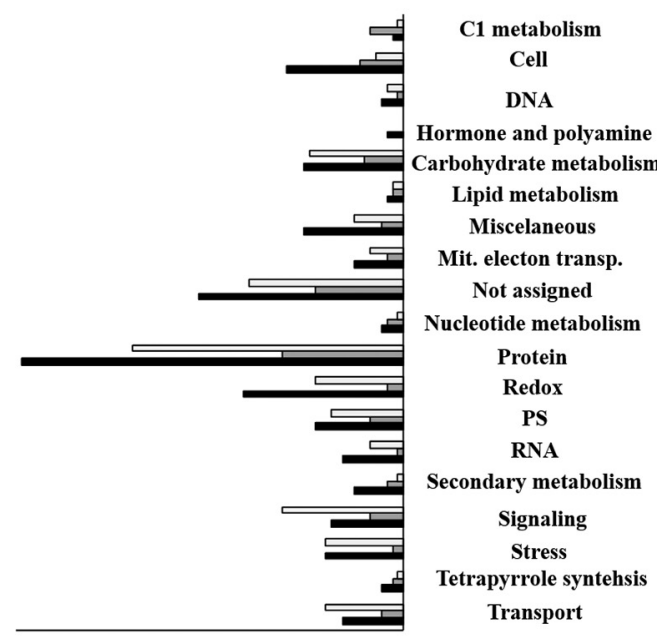

INCREASE

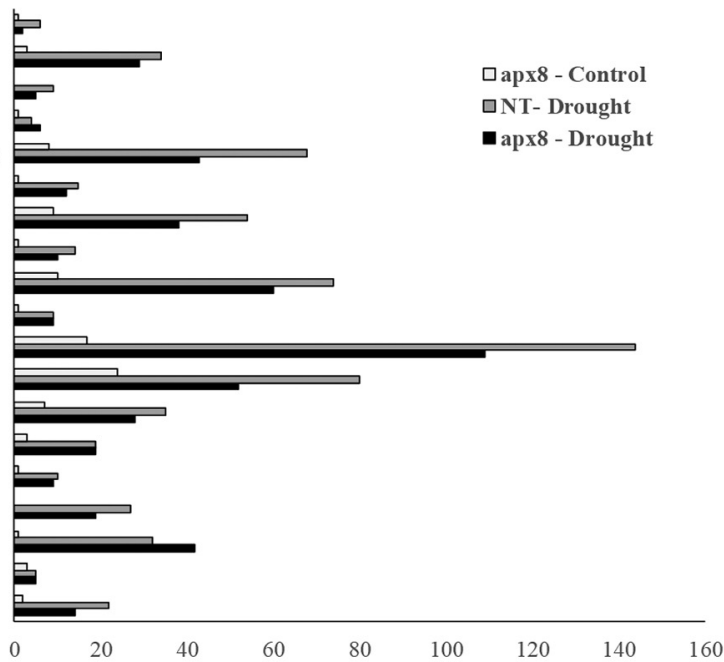

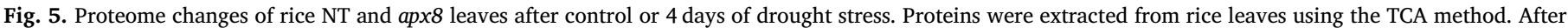

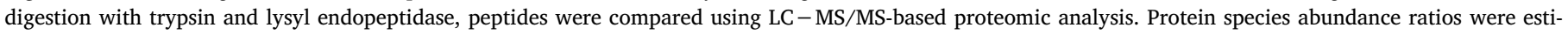

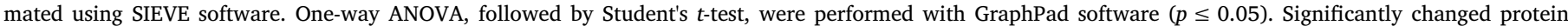

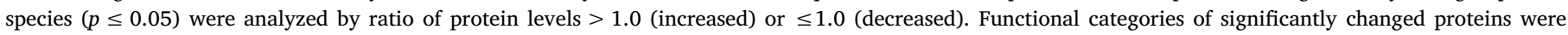
performed using MapMan ontology.

maximum Rubisco carboxylation (Vcmax) and maximum electron transport (Jmax), obtained from $\mathrm{P}_{\mathrm{N}}-\mathrm{Ci}$ fitted curves (Supplementary Fig. 3). In addition, drought induced strong increase in photorespiration rates $(\mathrm{PR})$ and this raise was more prominent in silenced plants (Table 2). Conversely, the photochemical indicators, maximum (Fv/
Fm) and actual quantum efficiency of PSII (YII), did not change by effect of silencing or drought in the two genotypes (Fig. 7).

In this study plants suffered a mild water stress (withdraw for 4 days), as revealed by the values of membrane damage and relative water content in leaves (Supplementary Table S2). In these conditions,

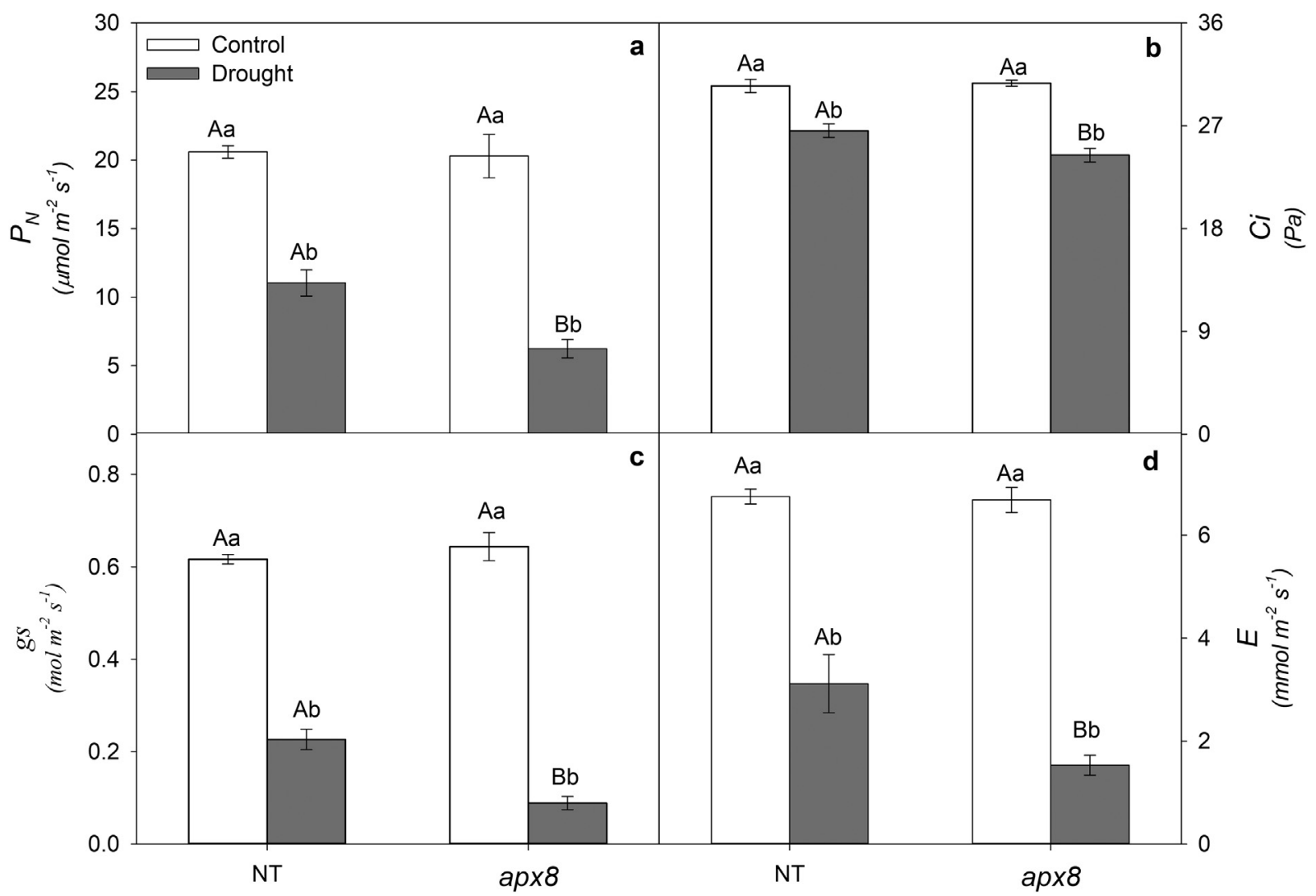

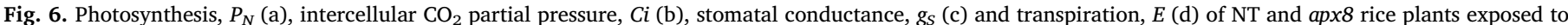

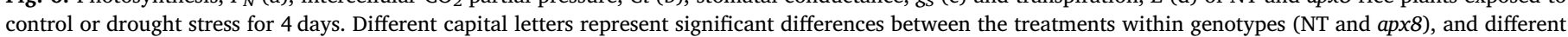

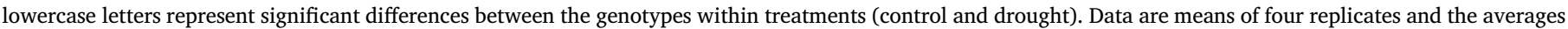
were compared using one-way ANOVA, followed by Tukey's test ( $p \leq 0.05)$. 
Table 2

$\mathrm{V}_{\text {cmax }}$ (in vivo Rubisco carboxylation rate), $\mathrm{J}_{\max }$ (maximum electron transport rate), $\mathrm{P}_{\mathrm{N}}$ (the maximum $\mathrm{CO}_{2}$ assimilation rate), $\mathrm{PR}$ (photorespiration) and gm (mesophyll conductance) of NT and apx8 rice plants exposed to control or drought stress for 4 days. Different capital letters represent significant differences between the treatments within lines (NT and apx8), and different lowercase letters represent significant differences between the lines within treatments (control and drought). Data are means of four replicates and the averages were compared using the Tukey's test, $(p \leq 0.05)$.

\begin{tabular}{lllllllllllll}
\hline & & $\mathrm{V}_{\mathrm{cmax}}$ & & $\mathrm{J}_{\max }$ & & $\mathrm{P}_{\text {Nmax }}$ & $\mathrm{PR}$ & & \multicolumn{2}{c}{$g m$} & \\
\hline \multirow{2}{*}{ NT } & Control & 156.1 & $\mathrm{Aa}$ & 111.8 & $\mathrm{Aa}$ & 24.9 & $\mathrm{Aa}$ & 20.2 & $\mathrm{Bb}$ & 10.2 & $\mathrm{Aa}$ \\
& Drought & 122.3 & $\mathrm{Bb}$ & 90.1 & $\mathrm{Bb}$ & 17.7 & $\mathrm{Bb}$ & 26.9 & $\mathrm{Ba}$ & 7.5 & $\mathrm{Ab}$ \\
\multirow{2}{*}{$a p x 8$} & Control & 144.8 & $\mathrm{Aa}$ & 109.5 & $\mathrm{Aa}$ & 24.4 & $\mathrm{Aa}$ & 27.6 & $\mathrm{Ab}$ & 11.3 & $\mathrm{Aa}$ \\
& Drought & 70.3 & $\mathrm{Cb}$ & 80.4 & $\mathrm{Cb}$ & 12.0 & $\mathrm{Cb}$ & 50.9 & $\mathrm{Aa}$ & 4.4 & $\mathrm{Bb}$ \\
& & & & & & & & & & & \\
\hline
\end{tabular}

$\mathrm{CO}_{2}$ assimilation is initially decreased by stomatal limitation and further by biochemical restriction in the Calvin-Benson cycle reactions, especially by decrease in Rubisco activity [43]. Previously, we have demonstrated that apx8 plants display high stomatal restriction associated to $\mathrm{H}_{2} \mathrm{O}_{2}$ accumulation in response to acute water deficit [18]. In this study, data suggest that higher reduction in photosynthetic $\mathrm{CO}_{2}$ assimilation in silenced plants is due to restriction in both stomatal and Rubisco activity, assuming that Vcmax is a good indicator for activity of this enzyme, as has been widely reported [44]. In parallel, the restriction for carboxylation and $\mathrm{CO}_{2}$ diffusion in silenced plants could have favored the Rubisco oxygenation activity, stimulating photorespiration [45] as was observed under drought condition. On the other hand, some reports have evidenced that $\mathrm{CO}_{2}$ assimilation reactions are limiting steps for photosynthesis compared to photochemical phase [12] and this feature could explain why the photochemistry did not change by effect of mild drought in silenced plants.

\subsection{Proteomic analysis reveals that drought induces increase in photosynthetic and photorespiration related-protein species}

To verify if the in vivo photosynthetic responses displayed by silenced and NT plants could be explained by changes at protein species profile level, proteomic analyses were performed. The results indicate that $60 \%$ of protein species involved in PS category are increased in apx8 plants under well-watered condition compared to NT (Fig. 5). After drought stress, proteomic analyses showed that both NT and ap $x 8$ plants presented great increase in PS-related protein species, but the former presented higher increased amount of protein species ( $96 \%$ and
$64 \%$, respectively). The drought-induced changes on the protein species levels belonging to Calvin-Benson, were not closely associated with in vivo $\mathrm{CO}_{2}$ assimilation measurements, in both silenced and NT plants. Indeed, despite Rubisco large subunit (N. 18), transketolase (N. 19), phosphoribulokinase (N. 20), aldolase (N. 22), fructose-bisphosphate aldolase (N. 23) and Rubisco activase (N. 25) have been increased in both genotypes (Table 1 ), $\mathrm{CO}_{2}$ assimilation rates decreased greatly especially in drought-stressed silenced plants. Interestingly, only chloroplastic triose phosphate isomerase (N. 21) was decreased in both genotypes, whereas sedoheptulase-1,7-bisphosphatase (N. 24) decreased only in apx8 plants.

The low correlation observed between in vivo $\mathrm{CO}_{2}$ measurements and changes in the amount of Calvin-Benson cycle protein species is possible since the majority of these enzymes are regulated post-translationally, especially by redox reactions via thioredoxins [46,47]. Moreover, Rubisco might be synthetized in amounts over the minimum required for its optimum activity and it may be accumulated in leaf tissues under stress condition as a storage protein $[12,48]$. The fact that sedoheptulase-1,7-bisphosphatase has been decreased in silenced plants, in parallel to decreases in $\mathrm{CO}_{2}$ assimilation and RuDP regeneration rates (estimated by Jmax), reinforces the importance of this enzyme for the Calvin-Benson cycle activity [49].

The proteomics also revealed that drought differentially affected the amount of photochemical protein species in silenced plants compared to NT plants despite the in vivo activity has remained unchanged. Indeed, some chlorophyll $a / b$ binding proteins (N.1, 3 and 4), PsbS (N. 5), PsbP (N.6), subunit IV of PSI reaction center (N. 7), cytochrome b6-f complex iron-sulfur subunit (N. 8), FNR (N. 9), plastocyanin (N. 10) and ATP synthase (N. 11 and 12) were increased by drought in both genotypes but they were more prominently enhanced in NT plants (Table 1). The low correlation between in vivo photochemical measurements and protein species abundance was previously reported in rice plants deficient in cytosolic APX exposed to high light [12]. These relationships are very complex since photochemical activity involves integrated actions of several protein species in a modular way and an isolated protein amount might not represent the activity in a physiological context.

The over-accumulation of some protective protein species might have favored the PSII activity. The elongation factor Tu (N. 44), an important protein involved in the translation of chloroplastic genome encoded protein species, was greatly increased in both drought-stressed genotypes but its abundance was prominently higher in silenced plants. This response occurred in parallel to some important heat shock proteins, HSP10 (N. 27), HSP70 (N. 28 and 29) and HSP90 (N. 30 and 31),

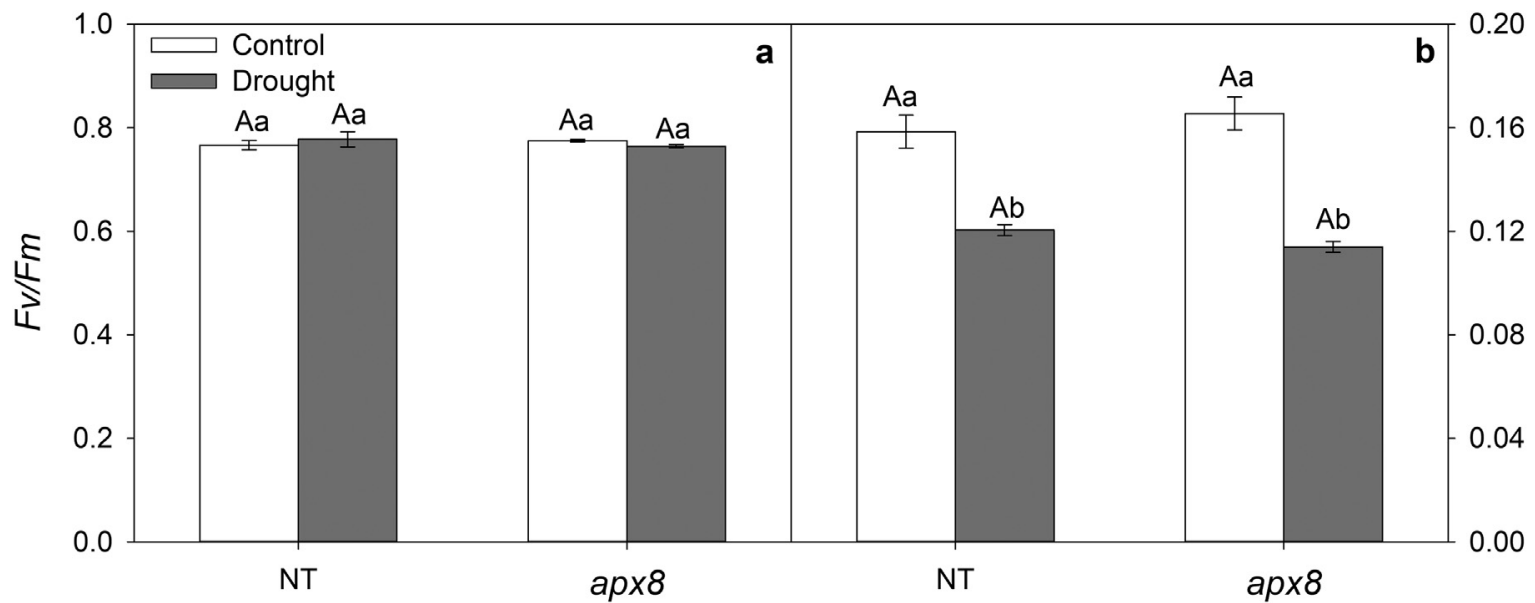

0.20

.12

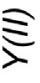

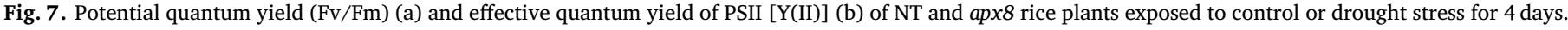

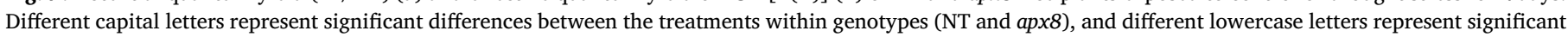

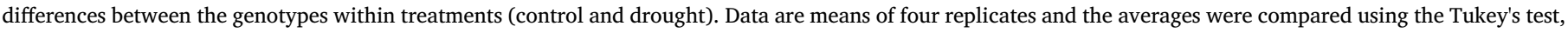
$(p \leq 0.05)$. 


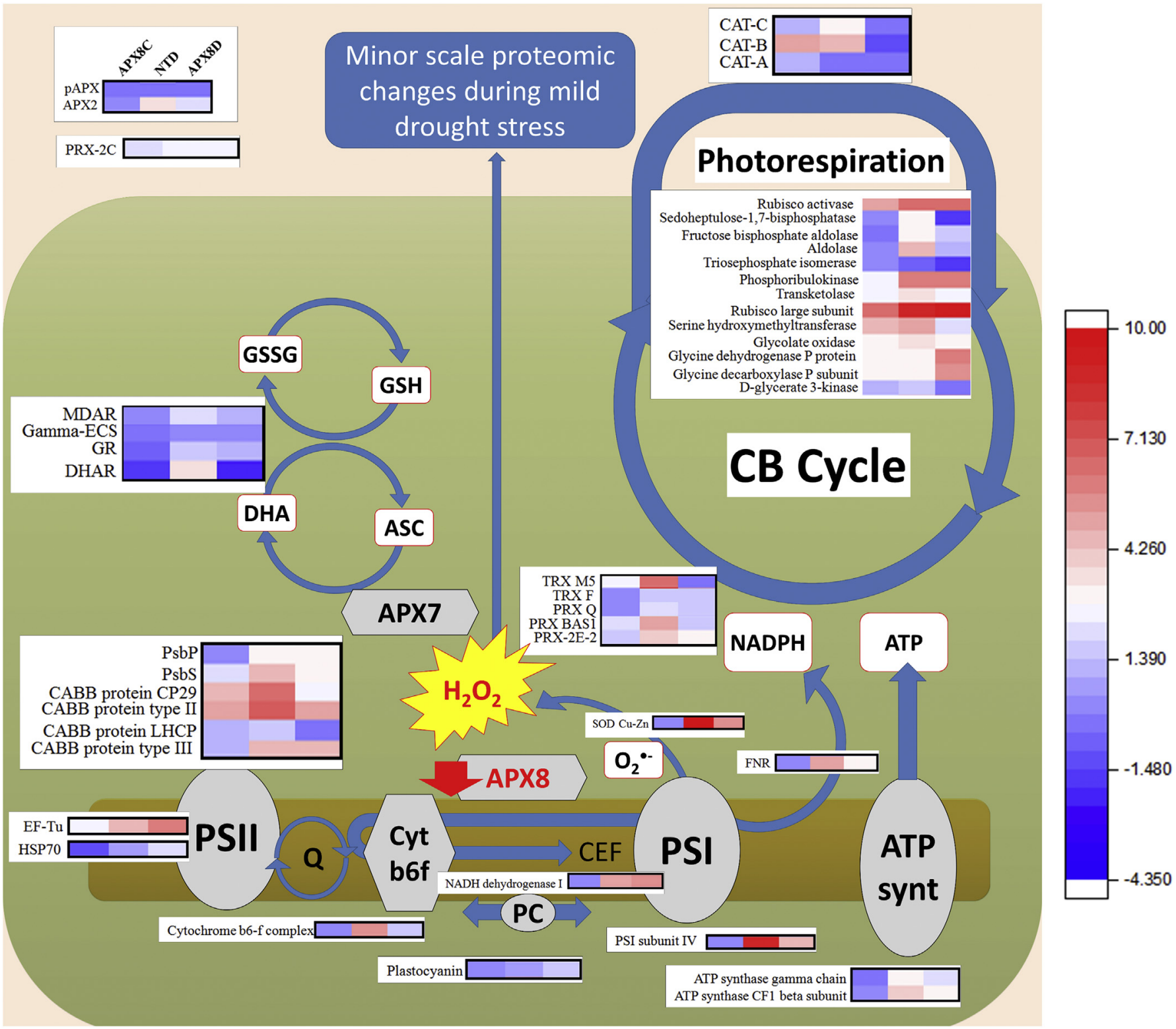

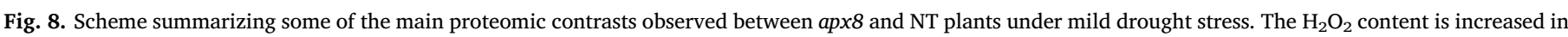

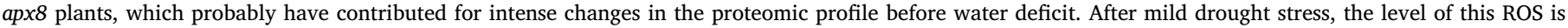

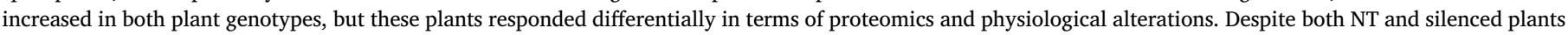

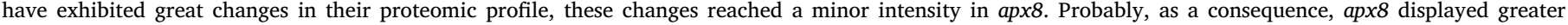

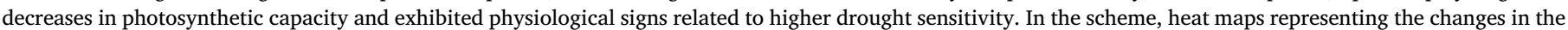

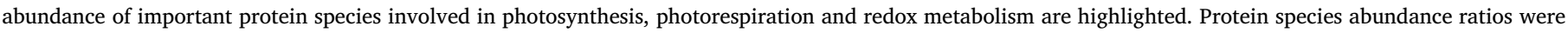

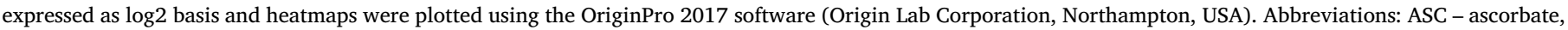

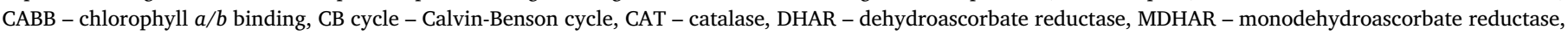
GSH - glutathione, PRX - peroxiredoxin, TRX - thioredoxin, pAPX - peroxisomal APX, CEF - cyclic electron flow and HSP - heat shock protein.

which were strongly increased in drought-stressed apx 8 plants. The over-accumulation of these protein species could have contributed to synthesis and stability of PSII proteins [50,51] and, consequently favoring photoprotection and activity of PSII in absence or deficiency of thylakoidal APX.

The NADH dehydrogenase (NDH) complex (N. 26) amount was increased by drought effect in both genotypes but it was more notably increased in silenced plants. This protein displays a key role in cyclic electron flow (CEF) of PSI contributing for energy dissipation, ATP synthesis and photoprotection [52]. Thus, the response displayed by apx8 plants could represent part of a compensatory mechanism for thylakoidal APX deficiency since this enzyme plays a crucial role in the water-water cycle (WWC), involved in energy dissipation and photoprotection [3]. An increased CEF activity could contribute to keep unchanged PSII quantum efficiency in drought-stressed silenced plants even in presence of significant impairment in $\mathrm{CO}_{2}$ assimilation.

Similar to the noticed for $\mathrm{CO}_{2}$ assimilation and photochemical activity measured in vivo, the trend of photorespiration estimated by gas exchange was not well correlated with abundance of some photorespiratory-protein species in drought-stressed plants. Indeed, silenced plants grown in well-watered conditions exhibited higher values of photorespiration rate than NT plants and this was positively associated with higher amounts of some important photorespiratory protein species: glycerate kinase (N. 13), glycine dehydrogenase - P protein (N. 15), glycolate oxidase (N. 16) and serine hydroxymethyltransferase (N. 17). Nevertheless, in drought condition, when the photorespiration rate 
intensely increased in apx8 plants compared to NT plants, only glycine dehydrogenase was increased. Photorespiration is an important process for dissipation of excess energy and ATP in C3 plants under drought stress [53] and, thus, this mechanism might have contributed for photoprotection in drought-stressed $a p x 8$ plants.

The PCA results suggest that apparently silenced plants displayed restrict phenotypic plasticity to cope with mild drought and, as a consequence, they are less able to perform effective responses, compared to NT plants. An important example for explains this condition is the limitation in antioxidant and photosynthetic capacity exhibited by rice plants deficient in thylakoidal APX. The phenotypic plasticity of these plants is apparently not enough to perform an effective protection against adverse effects induced by a mild stress, as that performed by NT plants.

3.6. OsApx8 silencing decreased protein species involved in ASC-GSH cycle leading to metabolic rearrangement of different peroxidases for partial APX8 compensation

This proteomic analysis was performed to evaluate if silencing of OsApx is able to trigger a compensatory mechanism involving other antioxidant protein species, especially under drought conditions. In the well-watered conditions, the silenced plants increased the amount of the following protein species: peroxiredoxin $2 \mathrm{C}$ (N. 68), peroxiredoxin 2E II (N. 69), 2-cys Prx (N. 70), catalases A, B and C (N. 71, 72 and 73) and thioredoxin M5 (N. 79). Under drought conditions, the redox protein species displayed two trends: a group was increased in both genotypes but NT exhibited higher amount. In this group are cytosolic APX2 isoform (N. 63), glutathione reductase (N. 66), glutamate cysteine ligase (N. 67), peroxiredoxin 2E II (N. 69), 2-cys Prx (N. 70), MnSOD (N. 74), monodehydroascorbate reductase (N. 75), Prx Q (N. 76), thioredoxin $\mathrm{F}(\mathrm{N}$. 77) and $\mathrm{Cu} / \mathrm{Zn}-\mathrm{SOD}(\mathrm{N} .78)$. The other group includes protein species that were increased in NT but decreased in the silenced plants: dehydroascorbate reductase (N. 65), CAT B (N. 72), CAT C (N. 73) and thioredoxin M5 (N. 79).

The literature has already proposed possible involvement of other peroxidases, such as glutathione peroxidase (GPX) and peroxiredoxins (Prx), involved in $\mathrm{H}_{2} \mathrm{O}_{2}$ homeostasis and signaling [13,39]. For instance, redundant pathways for ROS protection may exist in an attempt to compensate for the lack of important antioxidant enzymes, such as chloroplastic APXs. In fact, mechanisms such as ASC-GSH cycle have important roles in defending oxidative damage and balancing the redox status of ascorbate and glutathione under control and abiotic stresses [54]. It is well known that an efficient antioxidant system in chloroplasts and cytosol is vital for photosynthetic protection [10,55]. Thus, balancing of ROS production and detoxification in chloroplasts is crucial during stressful and non-stressful conditions. Here, NT plants showed much more increased protein species related to antioxidant response after drought stress (85.4\%) than apx8 after single silencing and drought stress (35\% and 64\%, respectively). This result demonstrates that reducing $O s A p x 8$ expression triggered major changes in plant redox-related mechanisms in rice plants and this probably led to a more sensitive phenotype of apx8 plants after mild drought stress.

Although rice silenced plants have increased the amount of some important peroxidases under well-watered conditions, this mechanism is apparently not enough for a full redox compensation to cope with a mild water deficit. Indeed, in this circumstance, $\mathrm{H}_{2} \mathrm{O}_{2}$ is accumulated and lipid peroxidation is increased in parallel to membrane damage in leaves of both genotypes but these changes are more intense in silenced plants. The proteomic responses indicate that apparently this changed redox homeostasis is not able to trigger signaling and antioxidant protection mechanisms as that triggered by non-transformed plants, reinforcing that thylakoidal APX isoform might be part of a signaling mechanism involved in several physiological processes. In this vein, it could participate of the regulation of $\mathrm{H}_{2} \mathrm{O}_{2}$ homeostasis mediating the abundance steady state of several protein species. Fig. 8 presents a scheme highlighting the main differences in redox, photosynthesis and photorespiration related to changes in protein species abundance triggered by apx 8 and NT plants in response to a mild drought.

\section{Conclusion}

Rice thylakoidal APX displays a central role in the regulation of abundance steady state of several important protein species, especially in response to a mild water deficit. In this physiological circumstance, some crucial processes are adjusted in a minor scale in APX8 deficient plants, compared to non-transformed plants. This feature contributes to compromising the functioning of key metabolic pathways especially those involved with photosynthesis, photorespiration and redox protection. The obtained data reinforce that thylakoidal APX could display an overall signaling role in plant cells, besides its canonical function as a chloroplastic peroxidase. These roles displayed by thylakoidal APX are essential to plants coping with mild water deficit, a common challenge for plants in field conditions.

\section{Conflict of interest statement}

The authors declare that they have no conflict of interest.

\section{Acknowledgements}

This research was supported by INCT Plant Stress Biotech (Conselho de Desenvolvimento Científico e Tecnológico) Proc. 465480/2014-4 and Fundação Cearense de Apoio ao Desenvolvimento Científico e Tecnológico (FUNCAP) for funding. FELC is supported by FUNCAP/ CAPES (Bolsista CAPES/BRASIL - Proc. 88887.162856/2018-00).

\section{Appendix A. Supplementary data}

Supplementary data to this article can be found online at https:// doi.org/10.1016/j.jprot.2018.08.014.

\section{References}

[1] S. Shigeoka, T. Ishikawa, M. Tamoi, Y. Miyagawa, T. Takeda, Y. Yabuta, K. Yoshimura, Regulation and function of ascorbate peroxidase isoenzymes, J. Exp. Bot. 53 (2002) 1305-1319, https://doi.org/10.1093/jexbot/53.372.1305.

[2] F.K. Teixeira, L. Menezes-Benavente, V.C. Galvão, R. Margis, M. Margis-Pinheiro, Rice ascorbate peroxidase gene family encodes functionally diverse isoforms localized in different subcellular compartments, Planta 224 (2006) 300-314, https:// doi.org/10.1007/s00425-005-0214-8.

[3] T. Maruta, Y. Sawa, S. Shigeoka, T. Ishikawa, Diversity and evolution of ascorbate peroxidase functions in chloroplasts: more than just a classical antioxidant enzyme? Plant Cell Physiol. 57 (2016) 1377-1386, https://doi.org/10.1093/pcp/pcv203.

[4] S. Kitajima, Hydrogen peroxide-mediated inactivation of two chloroplastic peroxidases, ascorbate peroxidase and 2-Cys peroxiredoxin, Photochem. Photobiol. 84 (2008) 1404-1409, https://doi.org/10.1111/j.1751-1097.2008.00452.x.

[5] Y.-F.F. Cai, Q.-Y.Y. Yang, S.-F.F. Li, J.-H.H. Wang, W. Huang, The water-water cycle is a major electron sink in Camellia species when $\mathrm{CO}_{2}$ assimilation is restricted, $\mathrm{J}$. Photochem. Photobiol. B Biol. 168 (2017) 59-66, https://doi.org/10.1016/j. jphotobiol.2017.01.024.

[6] K. Asada, The water-water cycle in chloroplasts: scavenging of active oxygens and dissipation of excess photons, Annu. Rev. Plant Physiol. Plant Mol. Biol. 50 (1999) 601-639, https://doi.org/10.1146/annurev.arplant.50.1.601.

[7] C. Miyake, Alternative electron flows (water-water cycle and cyclic electron flow around PSI) in photosynthesis: molecular mechanisms and physiological functions, Plant Cell Physiol. 51 (2010) 1951-1963, https://doi.org/10.1093/pcp/pcq173.

[8] L. Giacomelli, A. Masi, D.R. Ripoll, M.J. Lee, K.J. Van Wijk, Arabidopsis thaliana deficient in two chloroplast ascorbate peroxidases shows accelerated light-induced necrosis when levels of cellular ascorbate are low, Plant Mol. Biol. 65 (2007) 627-644, https://doi.org/10.1007/s11103-007-9227-y.

[9] S. Kangasjärvi, A. Lepistö, K. Hännikäinen, M. Piippo, E.-M.M. Luomala, E.M.M. Aro, E. Rintamäki, Diverse roles for chloroplast stromal and thylakoid-bound ascorbate peroxidases in plant stress responses, Biochem. J. 412 (2008) 275-285, https://doi.org/10.1042/BJ20080030.

[10] T. Maruta, A. Tanouchi, M. Tamoi, Y. Yabuta, K. Yoshimura, T. Ishikawa, S. Shigeoka, Arabidopsis chloroplastic ascorbate peroxidase isoenzymes play a dual role in photoprotection and gene regulation under photooxidative stress, Plant Cell Physiol. 51 (2010) 190-200, https://doi.org/10.1093/pcp/pcp177.

[11] A. Caverzan, A. Bonifacio, F.E.L. Carvalho, C.M.B. Andrade, G. Passaia, 
M. Schünemann, F.D.S.F. dos S. Maraschin, M.O. Martins, F.K. Teixeira, R. Rauber, R. Margis, J.A.G. Silveira, M. Margis-Pinheiro, The knockdown of chloroplastic ascorbate peroxidases reveals its regulatory role in the photosynthesis and protection under photo-oxidative stress in rice, Plant Sci. 214 (2014) 74-87, https://doi. org/10.1016/j.plantsci.2013.10.001.

[12] F.E.L. Carvalho, C.W. Ribeiro, M.O. Martins, A. Bonifacio, C.C. Staats, C.M.B. Andrade, J.V. Cerqueira, M. Margis-Pinheiro, J.A.G. Silveira, Cytosolic APX knockdown rice plants sustain photosynthesis by regulation of protein expression related to photochemistry, Calvin cycle and photorespiration, Physiol. Plant. 150 (2014) 632-645, https://doi.org/10.1111/ppl.12143.

[13] A. Bonifacio, M.O. Martins, C.W. Ribeiro, A.V. Fontenele, F.E.L. Carvalho, M. Margis-Pinheiro, J.A.G. Silveira, Role of peroxidases in the compensation of cytosolic ascorbate peroxidase knockdown in rice plants under abiotic stress, Plant Cell Environ. 34 (2011), https://doi.org/10.1111/j.1365-3040.2011.02366.x chamncha.

[14] R.H.V.V. Sousa, F.E.L. Carvalho, C.W. Ribeiro, G. Passaia, J.R. Cunha, Y. LimaMelo, M. Margis-Pinheiro, J.A.G. Silveira, Peroxisomal APX knockdown triggers antioxidant mechanisms favourable for coping with high photorespiratory $\mathrm{H}_{2} \mathrm{O}_{2}$ induced by CAT deficiency in rice, Plant Cell Environ. 38 (2015) 499-513, https:// doi.org/10.1111/pce.12409.

[15] C.H. Danna, C.G. Bartoli, F. Sacco, L.R. Ingala, G.E. Santa-María, J.J. Guiamet, R.A. Ugalde, Thylakoid-bound ascorbate peroxidase mutant exhibits impaired electron transport and photosynthetic activity, Plant Physiol. 132 (2003) 2116-2125, https://doi.org/10.1104/pp.103.021717.

[16] D. Todaka, K. Shinozaki, K. Yamaguchi-Shinozaki, Recent advances in the dissec tion of drought-stress regulatory networks and strategies for development of drought-tolerant transgenic rice plants, Front. Plant Sci. 6 (2015) 84, , https://doi. org/10.3389/fpls.2015.00084.

[17] C. Pinheiro, M.M. Chaves, Photosynthesis and drought: can we make metabolic connections from available data? J. Exp. Bot. 62 (2011) 869-882, https://doi.org/ 10.1093/jxb/erq340.

[18] D. Jardim-Messeder, A. Caverzan, R. Rauber, J.R. Cunha, F.E.L. Carvalho, M.L. Gaeta, G.C. da Fonseca, J.M. Costa, M. Frei, J.A.G. Silveira, R. Margis, N.J.M. Saibo, M. Margis-Pinheiro, Thylakoidal APX modulates hydrogen peroxide content and stomatal closure in rice (Oryza sativa L.), Environ. Exp. Bot. 150 (2018) 46-56, https://doi.org/10.1016/j.envexpbot.2018.02.012.

[19] D. Miki, K. Shimamoto, Simple RNAi vectors for stable and transient suppression of gene function in rice, Plant Cell Physiol. 45 (2004) 490-495, https://doi.org/10. 1093/pcp/pch048.

[20] N.M. Upadhyaya, B. Surin, K. Ramm, J. Gaudron, P.H.D. Schünmann, W. Taylor, P.M. Waterhouse, M.-B. Wang, Agrobacterium-mediated transformation of Australian rice cultivars Jarrah and Amaroo using modified promoters and selectable markers, Funct. Plant Biol. 27 (2000) 201, https://doi.org/10.1071/PP99078.

21] D.R. Hoagland, D.I. Arnon, The water-culture method for growing plants without soil, Calif. Agric. Exp. Stn. Circ. 347 (1950) 1-32 (doi:citeulike-article-id:9455435).

[22] J.A.G. Silveira, S.A.M. Araújo, J.P.M.S. Lima, R.A. Viégas, Roots and leaves display contrasting osmotic adjustment mechanisms in response to NaCl-salinity in Atriplex nummularia, Environ. Exp. Bot. 66 (2009) 1-8, https://doi.org/10.1016/j. envexpbot.2008.12.015.

[23] A. Blum, A. Ebercon, Cell membrane stability as a measure of drought and heat tolerance in wheat, Crop Sci. 21 (1981) 43-47, https://doi.org/10.2135/ cropsci1981.0011183X002100010013x.

[24] K.J. Livak, T.D. Schmittgen, Analysis of relative gene expression data using realtime quantitative PCR and the 2- $\Delta \Delta$ CT method, Methods 25 (2001) 402-408, https://doi.org/10.1006/meth.2001.1262.

[25] T.D. Schmittgen, K.J. Livak, Analyzing real-time PCR data by the comparative CT method, Nat. Protoc. 3 (2008) 1101-1108, https://doi.org/10.1038/nprot.2008.73.

[26] K. Amako, G.-X. Chen, K. Asada, Separate assays specific for ascorbate peroxidase and guaiacol peroxidase and for the chloroplastic and cytosolic isozymes of ascorbate peroxidase in plants, Plant Cell Physiol. 35 (1994) 497-504, https://doi.org/ 10.1093/oxfordjournals.pcp.a078621.

[27] C. Miyake, K. Asada, Inactivation mechanism of ascorbate peroxidase at low concentrations of ascorbate; hydrogen peroxide decomposes compound I of ascorbate peroxidase, Plant Cell Physiol. 37 (1996) 423-430, https://doi.org/10.1093/ oxfordjournals.pcp.a028963.

[28] M. Zhou, Z. Diwu, N. Panchuk-Voloshina, R.P. Haugland, A stable nonfluorescent derivative of resorufin for the fluorometric determination of trace hydrogen peroxide: applications in detecting the activity of phagocyte NADPH oxidase and other oxidases, Anal. Biochem. 253 (1997) 162-168, https://doi.org/10.1006/abio.1997. 2391.

[29] I. Cakmak, W.J. Horst, Effect of aluminium on lipid peroxidation, superoxide dismutase, catalase, and peroxidase activities in root tips of soybean (Glycine max), Physiol. Plant. 83 (1991) 463-468, https://doi.org/10.1111/j.1399-3054.1991. tb00121.x.

[30] J. Flexas, M.F. Ortuño, M. Ribas-Carbo, A. Diaz-Espejo, I.D. Flórez-Sarasa, $\mathrm{H}$. Medrano, Mesophyll conductance to $\mathrm{CO}_{2}$ in Arabidopsis thaliana, New Phytol. 175 (2007) 501-511, https://doi.org/10.1111/j.1469-8137.2007.02111.x.

[31] T.D. Sharkey, C.J. Bernacchi, G.D. Farquhar, E.L. Singsaas, Fitting photosynthetic carbon dioxide response curves for C3 leaves, Plant Cell Environ. 30 (2007) 1035-1040, https://doi.org/10.1111/j.1365-3040.2007.01710.x.

[32] M. Bagard, D. Le Thiec, E. Delacote, M.-P.P. Hasenfratz-Sauder, J. Banvoy, J. Gérard, P. Dizengremel, Y. Jolivet, Ozone-induced changes in photosynthesis and photorespiration of hybrid poplar in relation to the developmental stage of the leaves, Physiol. Plant. 134 (2008) 559-574, https://doi.org/10.1111/j.1399-3054. 2008.01160.x.

[33] N.R. Baker, Chlorophyll fluorescence: a probe of photosynthesis in vivo, Annu. Rev. Plant Biol. 59 (2008) 89-113, https://doi.org/10.1146/annurev.arplant.59. 032607.092759.

[34] M.M. Bradford, A rapid and sensitive method for the quantitation of microgram quantities of protein utilizing the principle of protein-dye binding, Anal. Biochem 72 (1976) 248-254, https://doi.org/10.1016/0003-2697(76)90527-3.

[35] S. Komatsu, Y. Nanjoa, M. Nishimurab, Proteomic analysis of the flooding tolerance mechanism in mutant soybean, J. Proteome 79 (2013) 231-250, https://doi.org/ 10.1016/j.jprot.2012.12.023.

[36] Y. Zhang, Z. Wen, M.P. Washburn, L. Florens, Effect of dynamic exclusion duration on spectral count based quantitative proteomics, Anal. Chem. 81 (2009) 6317-6326, https://doi.org/10.1021/ac9004887.

[37] B. Usadel, A. Nagel, O. Thimm, H. Redestig, O.E. Blaesing, N. Palacios-Rojas, J. Selbig, J. Hannemann, M.C. Piques, D. Steinhauser, W.-R. Scheible, Y. Gibon, R. Morcuende, D. Weicht, S. Meyer, M. Stitt, Extension of the visualization tool MapMan to allow statistical analysis of arrays, display of coresponding genes, and comparison with known responses, Plant Physiol. 138 (2005) 1195-1204, https:// doi.org/10.1104/pp.105.060459.

[38] I. Murgia, D. Tarantino, C. Vannini, M. Bracale, S. Carravieri, C. Soave, Arabidopsis thaliana plants overexpressing thylakoidal ascorbate peroxidase show increased resistance to Paraquat-induced photooxidative stress and to nitric oxide-induced cell death, Plant J. 38 (2004) 940-953, https://doi.org/10.1111/j.1365-313X. 2004.02092.x.

[39] G. Miller, N. Suzuki, L. Rizhsky, A. Hegie, S. Koussevitzky, R. Mittler, Double mutants deficient in cytosolic and thylakoid ascorbate peroxidase reveal a complex mode of interaction between reactive oxygen species, plant development, and response to abiotic stresses, Plant Physiol. 144 (2007) 1777-1785, https://doi.org/ 10.1104/pp.107.101436.

[40] B. D'Autréaux, M.B. Toledano, ROS as signalling molecules: mechanisms that generate specificity in ROS homeostasis, Nat. Rev. Mol. Cell Biol. 8 (2007) 813-824, https://doi.org/10.1038/nrm2256.

[41] Y. Wu, M. Mirzaei, D. Pascovici, J.M. Chick, B.J. Atwell, P.A. Haynes, Quantitative proteomic analysis of two different rice varieties reveals that drought tolerance is correlated with reduced abundance of photosynthetic machinery and increased abundance of ClpD1 protease, J. Proteome 143 (2016) 73-82, https://doi.org/10. 1016/j.jprot.2016.05.014.

[42] P.M. Mullineaux, Spatial dependence for hydrogen peroxide-directed signaling in light-stressed plants, Plant Physiol. 141 (2006) 346-350, https://doi.org/10.1104/ pp.106.078162.

[43] J. Flexas, J. Bota, F. Loreto, G. Cornic, T.D. Sharkey, Diffusive and metabolic lim itations to photosynthesis under drought and salinity in C3 plants, Plant Biol. 6 (2004) 269-279, https://doi.org/10.1055/s-2004-820867.

[44] M.C. Lima Neto, A.K.M. Lobo, M.O. Martins, A.V. Fontenele, J.A.G. Silveira, Dissipation of excess photosynthetic energy contributes to salinity tolerance: comparative study of salt-tolerant Ricinus communis and salt-sensitive Jatropha curcas, J. Plant Physiol. 171 (2014) 23-30, https://doi.org/10.1016/j.jplph.2013. 09.002.

[45] U. Heber, R. Bligny, P. Streb, R. Douce, Photorespiration is essential for the protection of the photosynthetic apparatus of $\mathrm{C} 3$ plants against photoinactivation under sunlight, Bot. Acta. 109 (1996) 307-315, https://doi.org/10.1111/j.1438 8677.1996.tb00578.x

[46] P.E. López-Calcagno, T.P. Howard, C.A. Raines, The CP12 protein family: a thioredoxin-mediated metabolic switch? Front. Plant Sci. 5 (2014) 9, , https://doi.org/ 10.3389/fpls.2014.00009.

[47] M.J. García-Murria, H.P.K. Sudhani, J. Marín-Navarro, M.M. Sánchez Del Pino, J. Moreno, Dissecting the individual contribution of conserved cysteines to the redox regulation of RubisCO, Photosynth. Res. 137 (2018) 251-262, https://doi. org/10.1007/s11120-018-0497-9.

[48] J.A.G. Silveira, F.E.L. Carvalho, Proteomics, photosynthesis and salt resistance in crops: an integrative view, J. Proteome 143 (2016) 24-35, https://doi.org/10. 1016/j.jprot.2016.03.013.

[49] L. Feng, Y. Han, G. Liu, B. An, J. Yang, G. Yang, Y. Li, Y. Zhu, Overexpression of sedoheptulose-1,7-bisphosphatase enhances photosynthesis and growth under salt stress in transgenic rice plants, Funct. Plant Biol. 34 (2007) 822-834, https://doi. org/10.1071/FP07074.

[50] H. Jimbo, R. Yutthanasirikul, T. Nagano, T. Hisabori, Y. Hihara, Y. Nishiyama, Oxidation of translation factor EF-Tu inhibits the repair of photosystem II, Plant Physiol. 176 (2018), 00037.2018 https://doi.org/10.1104/pp.18.00037.

[51] P. Pulido, E. Llamas, M. Rodriguez-Concepcion, Both Hsp70 chaperone and Clp protease plastidial systems are required for protection against oxidative stress, Plant Signal. Behav. 12 (2017) 1-4, https://doi.org/10.1080/15592324.2017.1290039.

[52] G. Finazzi, G.N. Johnson, Cyclic electron flow: facts and hypotheses, Photosynth. Res. 129 (2016) 227-230, https://doi.org/10.1007/s11120-016-0306-2.

[53] I. Voss, B. Sunil, R. Scheibe, A.S. Raghavendra, Emerging concept for the role of photorespiration as an important part of abiotic stress response, Plant Biol. 15 (2013) 713-722, https://doi.org/10.1111/j.1438-8677.2012.00710.x.

[54] C. Shan, S. Zhang, X. Ou, The roles of $\mathrm{H}_{2} \mathrm{~S}$ and $\mathrm{H}_{2} \mathrm{O}_{2}$ in regulating AsA-GSH cycle in the leaves of wheat seedlings under drought stress, Protoplasma (2018), https:/ doi.org/10.1007/s00709-018-1213-5.

[55] B. Naranjo, A. Diaz-Espejo, M. Lindahl, F.J. Cejudo, Type-f thioredoxins have a role in the short-term activation of carbon metabolism and their loss affects growth under short-day conditions in Arabidopsis thaliana, J. Exp. Bot. 67 (2016) 1951-1964, https://doi.org/10.1093/jxb/erw017. 